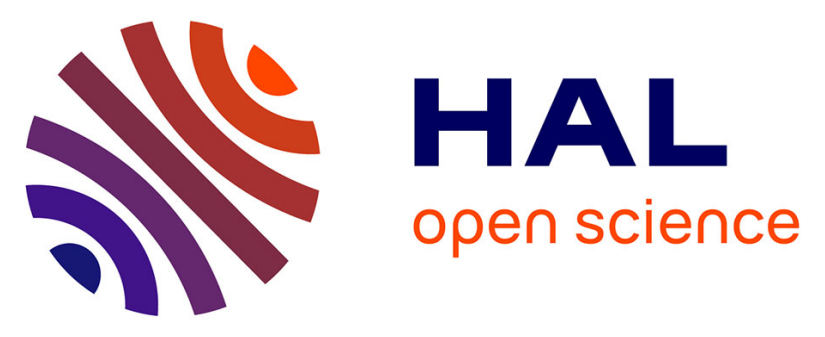

\title{
Study of the interface in natural fibres reinforced poly(lactic acid) biocomposites modified by optimized organosilane treatments
}

Nicolas Le Moigne, Marc Longerey, Jean-Marie Taulemesse, Jean-Charles Benezet, Anne Bergeret

\section{To cite this version:}

Nicolas Le Moigne, Marc Longerey, Jean-Marie Taulemesse, Jean-Charles Benezet, Anne Bergeret. Study of the interface in natural fibres reinforced poly(lactic acid) biocomposites modified by optimized organosilane treatments. Industrial Crops and Products, 2014, 52, pp.481-494. 10.1016/j.indcrop.2013.11.022 . hal-02914352

\section{HAL Id: hal-02914352 \\ https://hal.science/hal-02914352}

Submitted on 25 Jan 2021

HAL is a multi-disciplinary open access archive for the deposit and dissemination of scientific research documents, whether they are published or not. The documents may come from teaching and research institutions in France or abroad, or from public or private research centers.
L'archive ouverte pluridisciplinaire HAL, est destinée au dépôt et à la diffusion de documents scientifiques de niveau recherche, publiés ou non, émanant des établissements d'enseignement et de recherche français ou étrangers, des laboratoires publics ou privés. 


\title{
Study of the interface in natural fibres reinforced poly(lactic acid) biocomposites modified by optimized organosilane treatments
}

\author{
Nicolas Le Moigne*, Marc Longerey, Jean-Marie Taulemesse, \\ Jean-Charles Bénézet, Anne Bergeret** \\ Centre des Matériaux des Mines d'Alès (C2MA), Ecole des Mines d'Alès, 6 avenue de Clavières, F-30319 Alès Cedex, France
}

\begin{abstract}
A B S T R A C T
This study investigates the effect of optimized organosilane treatments on the surface properties of flax fibres and the resulting mechanical properties and interface modifications in flax fibres reinforced poly(lactic acid) (PLA) biocomposites. Optimizing the treatment conditions increases the hydrophobicity of the fibres, and improves significantly the mechanical properties of the biocomposites, while reducing largely the scattering. The origins of the reinforcement at the fibre/matrix interface are investigated at the macromolecular and the microstructural levels by physico-chemical and mechanical cross-analyses. It is shown that it results from both modified chemical coupling and mechanical interlocking at the fibre/matrix interface. Dynamic mechanical thermal analysis reveals a decrease in damping for treated biocomposites because of the formation of a layer of immobilized macromolecular chains resulting from strong interactions at the interface. In situ observations of crack propagation by scanning elec-tron microscopy illustrate clearly that the treated biocomposites show a cohesive interfacial failure at much higher loads, highlighting the enhanced load transfer from the PLA to the flax fibres.
\end{abstract}

PLA

Interface/interphase

Silane

\section{Introduction}

In the last decade, a growing interest has been shown for fully biobased and biodegradable composites based on natural fibres and thermoplastic biopolymer as poly(lactic acid) (PLA). Some products of natural fibres reinforced PLA are already on the market for various applications: automotive, mobile phone or plant pots (Graupner et al., 2009). This new class of composites is more environmental friendly due to the lowest environmental impacts of both natural fibres and PLA matrix during their production and use phases as well as their end of life (Dissanakaye et al., 2009; Joshi et al., 2004; Le Duigou et al., 2011, 2012a). Indeed, fully biobased and biodegradable composites can be either recycled, composted or incinerated. Although showing lower mechanical performances than conventional petroleum based thermoplastic composites reinforced with glass fibres, they present excellent specific mechanical properties thanks to their low density as well as interesting viscoelastic and acoustic damping performances. To

\footnotetext{
* Corresponding author. Tel.: +33(0)4 66785302.

** Corresponding author. Tel.: +33(0)4 66785344 .

E-mail addresses: nicolas.le-moigne@mines-ales.fr (N. Le Moigne), anne.bergeret@mines-ales.fr (A. Bergeret).

1 C2MA is member of the European Polysaccharide Network of Excellence (EPNOE), www.epnoe.eu.
}

better integrate these materials on an industrial scale, two main strategies can be developed to enhance their mechanical performances: (i) improving the intrinsic mechanical properties of the raw materials, i.e. natural fibres and PLA, and (ii) improving the interfacial adhesion in between.

Several recent studies showed that the natural fibres/PLA interface is intrinsically rather good. Le Duigou et al. (2010a,b, 2012b) found that the interfacial strength of flax/PLLA is higher than glass fibre/PLLA, possibly due to the rougher surface of flax fibre and lower thermal residual stresses after processing. Raj et al. (2011) also suggested that naturally occurring interactions, Van der Waals and hydrogen bonds between flax surface and carboxyl groups in PLA, could promote the adhesion in between. Besides, numerous studies deal with the improvement of interfacial adhesion in natural fibres reinforced composites to optimize their mechanical performances. Chemical as well as physical treatments have been developed to improve the reactivity and hence the interactions between the natural fibres and the matrix (Belgacem and Gandini, 2005; Faruk et al., 2012; Kalia et al., 2009). In the case of natural fibres/PLA composites, soft treatments as the water soaking of jute, kenaf and henequen fibres/PLA (Cho et al., 2007) and flax fibres/PLA (Le Duigou et al., 2012b) were investigated. The results showed that water treatment can improve the interfacial shear strength and the mechanical properties of the composites. Alkali treatment was also tested on hemp fibres/PLA (Hu and Lim, 2007) and bamboo fibres/PLA (Tokoro et al., 2008) and leads to 
Table 1

Main characteristics of the technical flax fibres used as given by $\mathrm{FRD}^{\circledR}$

Chemical composition according to norms NF V18-122, NF EN ISO 13906 (AFNOR, 1997, 2008)

\begin{tabular}{llll}
\hline Cellulose (wt\%) & Hemicelluloses (wt\%) & Extractives (pectins, waxes, fats) (wt\%) & Ash (wt\%) \\
\hline $80 \pm 1$ & $13 \pm 1$ & $4 \pm 1$ & $1 \pm 1$
\end{tabular}

Mechanical properties according to norm XP T 25-501-2 (AFNOR, 2009)

\begin{tabular}{lll}
\hline Young modulus (GPa) & Tensile strength (MPa) & Elongation at break (\%) \\
\hline $36 \pm 13$ & $750 \pm 490$ & $3.0 \pm 1.9$
\end{tabular}

improved moduli and ultimate strengths. Other authors investigated the effect of silane treatments on non-woven kenaf/PLA (Lee et al., 2009), and the effect of a combined alkali and silane treatment on kenaf sheet/PLA laminated composites (Huda et al., 2008) and ramie fibres/PLA (Yu et al., 2010). They obtained a significant improvement of the overall mechanical properties, the alkali and combined alkali/silane treatments giving the best results. The use of isocyanates was also studied in sugar beet pulp/PLA and resulted in increased mechanical properties and water resistance (Chen et al., 2008). Other approaches as the plasticizing of the PLA matrix to improve impact properties of flax fibres/PLA (Oksman et al., 2003; Wong et al., 2004) were also investigated and gave mixed results on mechanical properties. More environmental friendly fibre treatments as the use of enzymes in flax fibres/PLA (Raj et al., 2011) or bio-based coupling agents as lysine-diisocyanate in bamboo fibres/PLA (Lee and Wang, 2006) and dopamine in hemp fibres/PLA (Bourmaud et al., 2009), or the use of xyloglucan as an initiator for the synthesis of polymers from cellulose surfaces (Zhou et al., 2005) are also under study.

Among all these treatments, organosilanes used for many years at the industrial scale for glass fibres, are promising and versatile coupling agents that could improve the interface in various natural fibres reinforced composites. The organofunctionality of silanes must be adapted to achieve a chemical bonding with the polymer matrix used (Xie et al., 2010). However, a review of literature shows that the conditions of organosilane treatments applied to natural fibres are not well controlled (Belgacem and Gandini, 2005) and vary widely, leading in several cases to a limited enhancement of the interface and hence of the biocomposites properties. The only comprehensive studies on silane treatments have been conducted by Abdelmouleh et al. (2002, 2004). The authors investigated the kinetic of silanes adsorption and grafting on pure cellulose substrates and also lignin substrates (Castellano et al., 2004) and developed enhanced treatments to reinforce a low density polyethylene and a natural rubber matrix (Abdelmouleh et al., 2007). Improved mechanical performances were obtained when silanes were covalently bonded with the matrix, whereas entanglements with an organosilane bearing aliphatic chains were not efficient. Valadez-Gonzalez et al. (1999a,b) also conducted a detailed study on silane treated henequen fibres to reinforce high density polyethylene. The grafting efficiency of silanes was investigated and interfacial shear and tensile strengths were enhanced when combining the silane treatment with an alkaline pre-treatment. These studies remain focused on polyolefin based composites reinforced with natural fibres or cellulose substrates having limited mechanical properties and not intended to be incorporated in biocomposites for technical applications.

Flax fibres are nowadays the most advanced natural technical fibres. They indeed present high modulus and tensile stress (Baley, 2002; Faruk et al., 2012). They can be used as short fibres in thermoplastics for injection moulding applications and can also be transformed in complex technical fabrics to be impregnated and formed with thermosets and thermoplastics. In this study, we investigate the influence of the conditions of silane treatments on the mechanical performances of short flax fibres/PLA biocomposites for injection moulding applications. A detailed study of the surface modifications of flax fibres is conducted as a function of different treatment parameters: concentration and temperature of the organosilane solution, soaking time and heating temperature, alkaline pre-treatment. Then, the mechanical properties of the resulting biocomposites produced at the pilot scale are evaluated. Finally, the origins of the reinforcement and the role of the interface are characterized and discussed.

\section{Materials and methods}

\subsection{Materials}

A biodegradable, thermoplastic matrix poly(lactic acid), NatureWorks Ingeo ${ }^{\mathrm{TM}}$ PLA polymer 7000D, supplied by Resinex (France) was used in this study. It is a bottles grade resin designed for injection stretch blow moulded applications which present a density of $1.24 \mathrm{~g} / \mathrm{cm}^{3}$, a melting temperature of $145-155^{\circ} \mathrm{C}$ and a glass transition of $55-60^{\circ} \mathrm{C}$. Technical flax fibres, FIBRA-S6A, in the form of bundles of $6 \pm 0.5 \mathrm{~mm}$ in length and $260 \pm 150 \mu \mathrm{m}$ in diameter (RH 9.1-11\%) were supplied by Fibres Recherche Développement (FRD ${ }^{\circledR}$, France). Composition and mechanical properties are given in Table 1.

\subsection{Fibre treatment}

\subsubsection{Organosilane treatments}

The flax fibres were treated in various conditions with an organosilane coupling agent named GPS (Fig. 1), (3glycidyloxypropyl) trimethoxysilane (purity $>98 \%$ ), chosen for its reactivity with PLA (see Section 3.3.2) and supplied by Sigma-Aldrich (Dow Corning ${ }^{\circledR}$ product Z-6040). The influence of the concentration and temperature of the organosilane solution, the soaking time and the heating temperature were tested. The procedure of treatment was the following: the organosilane (at 1,5 or $10 \mathrm{wt} \%$ with respect to the fibre weight) were hydrolyzed under continuous stirring during $1 \mathrm{~h}$ in a $2 \mathrm{~L}$ ethanol (purity $>99.5 \%) /$ distilled water $(60 / 40, \mathrm{w} / \mathrm{w})$ bath adjusted to $\mathrm{pH}$ 5 with acetic acid, $150 \mathrm{~g}$ of flax fibre bundles were then soaked in the bath at defined soaking times ( $5 \mathrm{~min}, 1$ or $24 \mathrm{~h}$ ) and temperatures $\left(20\right.$ or $\left.70^{\circ} \mathrm{C}\right)$. For the test at $70^{\circ} \mathrm{C}$, the heating of the bath was started after the immersion of the fibres to limit the condensation of the silanes (Brochier Salon et al., 2008) prior to fibre introduction. Fibres were then washed until the $\mathrm{pH}$ was neutral, dried in a ventilated hood at room temperature during $24 \mathrm{~h}$ and cure (60

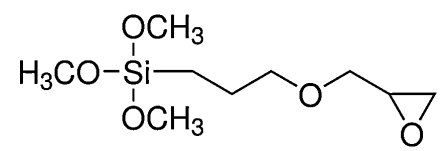

Fig. 1. Silane coupling agent used: (3-glycidyloxypropyl) trimethoxysilane named GPS 
Table 2

Designation of untreated and treated fibre bundles with their corresponding conditions of treatments. Figures in bold indicate the conditions that were compared for each treatment parameters, other conditions being fixed. Flax T2 is the reference treatment.

\begin{tabular}{|c|c|c|c|c|c|}
\hline \multirow[t]{2}{*}{ Fibre samples } & \multicolumn{5}{|c|}{ Tested treatment parameters } \\
\hline & Alkaline pre-treatment & Silane concentration (\%) (fibre weight basis) & Soaking time $(\mathrm{h})$ & Bath temp. $\left({ }^{\circ} \mathrm{C}\right)$ & Curing temp $\left({ }^{\circ} \mathrm{C}\right)$ \\
\hline Flax NT & No treatment & & & & 105 \\
\hline Flax $\mathrm{T} 1$ & No & 1 & 1 & 20 & 105 \\
\hline Flax T2 & No & 5 & 1 & 20 & 105 \\
\hline Flax T3 & No & 10 & 1 & 20 & 105 \\
\hline Flax T4 & No & 5 & 0.08 (5 min) & 20 & 105 \\
\hline Flax T5 & No & 5 & 24 & 20 & 105 \\
\hline Flax T6 & No & 5 & 1 & 20 & 60 \\
\hline Flax T7 & No & 5 & 1 & 70 & 105 \\
\hline Flax T8 & Yes & 5 & 1 & 20 & 105 \\
\hline
\end{tabular}

or $105^{\circ} \mathrm{C}$ ) in an air oven during $2 \mathrm{~h}$. No subsequent washing was achieved in order to limit the treatment steps and approach industrial conditions. Fibres were stored in a climatized chamber $(2 \%$ relative humidity). The different fibre treatment parameters tested in this work are resumed in Table 2. For Flax NT, Flax T7 and Flax T8, $600 \mathrm{~g}$ of fibre bundles were treated by the same method repeated four times to be used for biocomposites preparation.

\subsubsection{Alkaline pre-treatment}

Prior to the organosilane treatment, the Flax T8 fibre sample was subjected to a gentle alkaline pre-treatment. Fibres were soaked for $1 \mathrm{~h}$ at room temperature in a $\mathrm{NaOH}$ aqueous solution $5 \%(\mathrm{w} / \mathrm{w})$ which appears to be an optimum $\mathrm{NaOH}$ concentration in literature (Faruk et al., 2012; Kabir et al., 2012; Li et al., 2007). Then, the fibres were washed until the $\mathrm{pH}$ was neutral and dried in a ventilated hood at room temperature during $24 \mathrm{~h}$. The sodium hydroxide $\mathrm{NaOH}$ (purity 98\%) was supplied by Sigma-Aldrich.

\subsection{Biocomposites preparation}

Blends of PLA loaded at 20 wt\% $(18.15 \%$, v/v) of Flax NT, Flax T7 and Flax T8 were compounded in a co-rotating twin-screw extruder BC21 (Clextral) equipped with a feeder system KCL-KL35 (K-Tron) specially designed for natural fibres dosage. The barrel to die temperature profile was $60-175^{\circ} \mathrm{C}$ with a screw speed of $300 \mathrm{rpm}$. The approximate residence time in the extruder was $75 \mathrm{~s}$. Prior to compounding, PLA matrix was dried at $80^{\circ} \mathrm{C}$ overnight to avoid its hydrolysis upon extrusion. Melted blends were cooled in a water bath at the exit of the die, then pelletized to $3 \mathrm{~mm}$ diameter and dried overnight at $50^{\circ} \mathrm{C}$ under vacuum ( $\left.100 \mathrm{mbar}\right)$. About $2 \mathrm{~kg}$ of granules were collected for each blend. Pelletized blends were moulded by injection with a Krauss Maffei KM-50-180-CX into test specimens (ISO 527-1A) for the measurement of the mechanical properties. Temperatures in the barrel and nozzle ranged from 180 to $210^{\circ} \mathrm{C}$, the screw speed was $80 \mathrm{rpm}$. Samples were maintained at 500 then 800 bars during $20 \mathrm{~s}$ and $15 \mathrm{~s}$ respectively. The cooling time was $15 \mathrm{~s}$ and the temperature of the mould was $25^{\circ} \mathrm{C}$.

\subsection{Fibre size and shape measurements}

Fibre size and shape distributions after compounding and injection were analyzed according to the methodology described by Le Moigne et al. (2011). The injected specimens were cut in small pieces and $0.5 \mathrm{~g}$ of composite was dissolved in $20 \mathrm{ml}$ of chloroform in a round-bottom flask. The dissolution took place under gentle mixing using a magnetic stirrer. After total dissolution (30 min), several droplets were taken from the mixture and deposited on glass slides. The stirring of the mixture was adjusted to $400 \mathrm{rpm}$ to ensure a good convection and to avoid the precipitation of large fibres when taking probes from the flask. Glass slides were then covered with glass lamellas before microscopic observations. Fibre observations were performed with a Leica Laborlux 11 POL S optical microscope in transmission mode equipped with a high resolution 3-CCD numerical camera (JVC KY-F55BE). Crossed polarizers were used to enhance the contrast and help the outline detection of cellulosic fibres which are birefringent under polarized light. As shown in Fig. 2a, the resulting pictures have a black background with well defined white birefringent fibres and particles. Fibre size and shape distributions were analyzed by measuring each fibre length $(L)$ and width $(W)$ of about 1000 fibres from 10 to 20 pictures with the software Aphelion ${ }^{\mathrm{TM}}$ V.4.1.2 (ADCIS and Amerinex Applied Imaging), which automatically detects the outlines of each of tens fibres present on the pictures. Fibre length and width were determined as the maximum and minimum Ferret diameters, respectively. The overlapped fibres were excluded from the counts. As observed by Le Moigne et al. (2011), a large variation in the size and shape of the fibres was observed and two main entities can be defined: the elementary fibres consisting of one single long plant cell, and the particles having an aspect ratio comprised between 1 and 2 (see Fig. 2a). Because of the pictures resolution ( $2.52 \mu \mathrm{m} /$ pixel $)$, the particles with the length smaller than $8 \mu \mathrm{m}$ were not considered in the fibre size distribution. As shown in Fig. 2b and c, the fibre length and aspect ratio after compounding were very similar for all the biocomposites studied.

\subsection{FTIR analysis}

Fourier Transform Infrared (FTIR) spectra of untreated and treated fibre bundles were recorded with a Bruker IFS66 spectrometer in attenuated total reflectance (ATR) mode. $1 \mathrm{~g}$ of fibre bundles was packed under 30 bars to form discs of $25 \mathrm{~mm}$ in diameter and $2 \mathrm{~mm}$ in thickness. This protocol avoids crushing and separating the bundles to analyze them in their initial form prior to compounding. Some studies (Abdelmouleh et al., 2004; Valadez-Gonzalez et al., 1999b) deal with FTIR analysis in DRIFT mode on silane treated cellulose substrates mixed with $\mathrm{KBr}$. The cellulose substrates used by Abdelmouleh et al. (2004) were already individualized fibres or microcrystalline cellulose (MCC) powders. FT-IR spectra of the samples were recorded in the range $4000-400 \mathrm{~cm}^{-1}$ with a resolution of $2 \mathrm{~cm}^{-1}$ and 32 scans. All the spectra were normalized according to the band at $2920 \mathrm{~cm}^{-1}$, assigned to $\mathrm{CH}_{2}$ stretching, which is usually used as a reference band for cellulose based substrates because it is unaffected by changes in sample preparation, crystallinity or humidity and shows a constant intensity (Nelson and O'Connor, 1964).

\subsection{Wettability measurements}

The wettability of the untreated and treated fibre bundles with ethanol was determined using a LPR 902 Wettability Meter (KSV Instruments LTD), based on the principle of capillary rise. As for FTIR analysis, we choose to characterize fibre bundles in order to analyze 


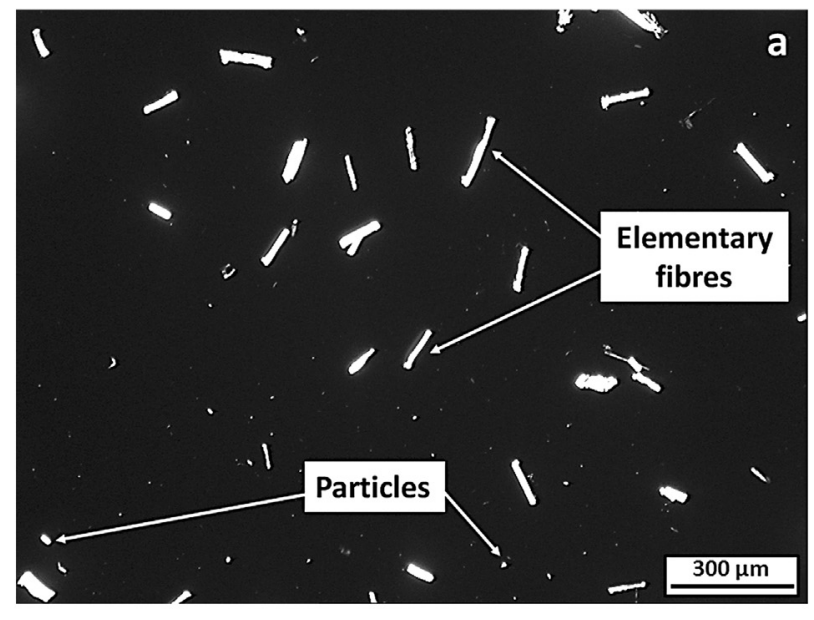

Fiber length $(\mu \mathrm{m})$

b

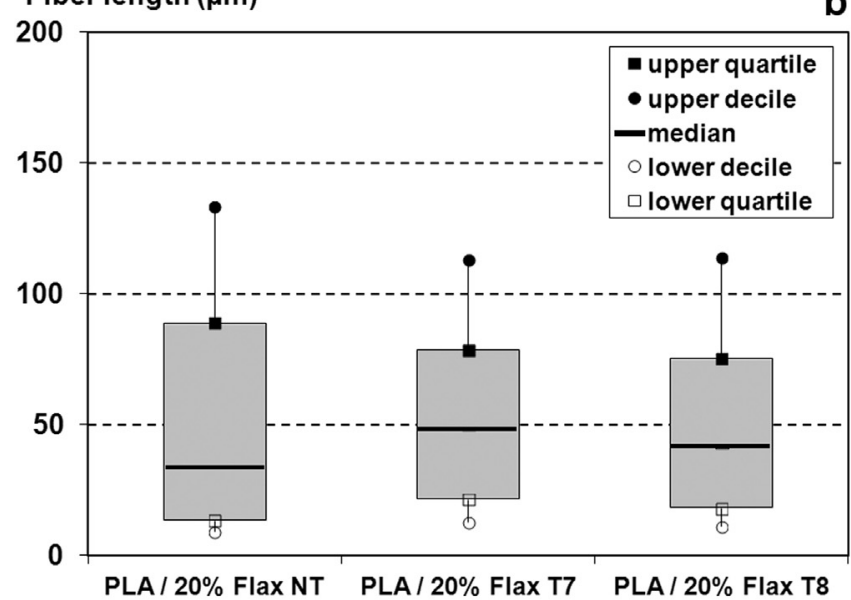

Aspect ratio (L/W)

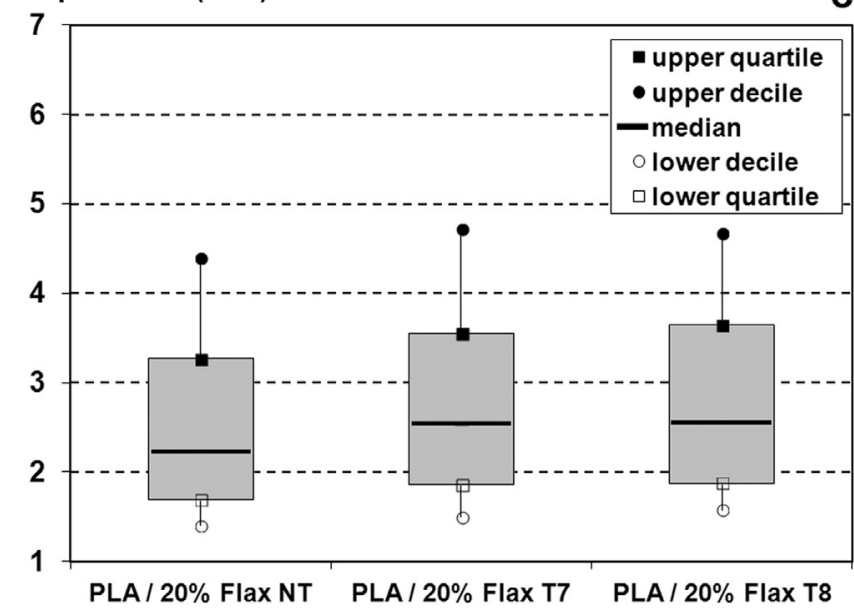

Fig. 2. (a) Example of picture obtained for diluted PLA/20\% Flax NT composite made with transmission polarized light optical microscopy, Box plots of (b) length and (c) aspect ratio distributions weighted in number for PLA/20\% Flax NT, T7 and T8 composites.

them in their initial state prior to compounding. $1 \mathrm{~g}$ of fibre bundles were placed in a tube and packed at a constant compacity by fixing a constant volume to mass ratio of fibres. This bed of fibres was then placed in contact with a bath of ethanol fed by a column of ethanol (purity $96 \%$, supplied by Legallais, France). During the capillary rise in the bed of fibres, a detector measures the decrease of ethanol in the column which corresponds to the absorbed volume of ethanol in the bed of fibres. The squared volume is plotted as a function of time. During the first few seconds of contact with the solvent, the curve is linear and its slope $A$ is expressed by the following equation:

$A=\frac{\eta}{\gamma_{L} * C * \cos \theta}$

where $\eta$ is the solvent viscosity, $C$ is a constant that depends on the packing of the particles and independent of the solvent used, $\gamma_{L}$ is the free surface energy of the solvent, $\theta$ is the contact angle. Knowing $\eta(1.1 \mathrm{mPas})$ and $\gamma_{L}(22.39 \mathrm{mN} / \mathrm{m})$ for ethanol at room temperature, the evolution of $C \cos \theta$ quantifies the wettability of the fibres with the solvent. At least five experiments were done for each fibre samples. This method allows to test a large number of fibres at the same time thus giving a good statistical determination of the fibre wettability as compared to other measurements made on single fibre or bundle and based on the Wilhelmy (Cantero et al., 2003) or the sessile drop (Zhou et al., 2012) techniques. It has to be emphasized that the capacity of natural fibres to absorb solvents and swell make the surface measurements delicate independent of the technique used. The solvents used for measurements can also partially dissolve some of the sugars present at the surface. The measurements must thus be taken in the first few seconds of contact between the solvent and the fibres to limit absorption, swelling and dissolving effects.

\subsection{Mechanical properties}

Tensile properties of the biocomposites were measured with a Zwick TH 010 testing machine equipped with an extensometer Zwick "clip-on" for the determination of the Young modulus. According to ISO 527 standard, the displacement speed was $1 \mathrm{~mm} / \mathrm{min}$ and $50 \mathrm{~mm} / \mathrm{min}$ for the determination of the Young modulus and the ultimate tensile strength, respectively. 10 samples per blend were tested for each testing procedure. Charpy impact test was performed on unnotched samples with a Zwick 5102 test machine equipped with a pendulum of $2 \mathrm{~J}$ according to ISO 179-1 standard. Charpy impact strength was measured on 15 samples per blend. Prior to mechanical tests, injected specimens were placed under room conditions during three days to relax any residual stresses.

\subsection{Differential scanning calorimetry (DSC)}

The crystallinity of injected specimens was investigated with a Perkin-Elmer Pyris Diamond DSC equipped with an Intracooler II using nitrogen as a purge gas. The temperature and heat flow were calibrated with indium. Samples of 15-20 mg were extracted in the section of the injected specimen, sealed in aluminium pans, and heated from 30 to $200^{\circ} \mathrm{C}$ at $10^{\circ} \mathrm{C} / \mathrm{min}$. 3 samples per blend were tested. The degree of crystallinity $X_{c}$ was determined according to the following equation:

$X_{c}=\left(\frac{\left|\Delta H_{m}\right|-\left|\Delta H_{c}\right|}{\left|\Delta H_{m}^{0}\right|}\right) \times 100$

where $\Delta H_{m}$ and $\Delta H_{c}$ are the melting enthalpy and the enthalpy of cold crystallization that occurs upon heating, respectively, and are expressed in $\mathrm{J} / \mathrm{g}$ of PLA in the biocomposites, i.e. $80 \%(\mathrm{w} / \mathrm{w})$. $\Delta H_{m}^{0}$ is the melting enthalpy of a pure PLA crystal and $\Delta H_{m}^{0}=93 \mathrm{~J} / \mathrm{g}$ (Fischer et al., 1973).

\subsection{X-ray diffraction}

Crystal structures of PLA, flax fibre bundles and biocomposites were investigated by X-ray diffraction (XRD) using an AXS D8 Advance Bruker diffractometer equipped with a $\mathrm{Cu}$ cathode 
$(\lambda=1.54 \AA)$. Measurements were performed directly on compressed fibres (discs of $25 \mathrm{~mm}$ in diameter and $2 \mathrm{~mm}$ in thickness) and injected specimens in the range $2 \theta=2.5-63.5^{\circ}$ with a step size of 0.01 .

\subsection{Dynamic mechanical thermal analysis (DMTA)}

The viscoelastic properties of the biocomposites were investigated using a VA 815 Metravib RDS in the dual cantilever bending mode. The composites behaviour at the fibre/matrix interface is indeed better detected in flexural deformation as fibres carried more load, especially in the case of unidirectional composites (Dong and Gauvin, 1993; Gerard et al., 1986, 1990; Reed, 1980). The samples were cut from injected specimens with dimensions of $55 \mathrm{~mm} \times 10 \mathrm{~mm} \times 4 \mathrm{~mm}$. The experiments were conducted in the linear viscoelastic domain at a strain value of $\pm 5 \mu \mathrm{m}$, i.e. $0.012 \%$. Measurements were performed at $5 \mathrm{~Hz}$, and the temperature was varied between 25 and $100^{\circ} \mathrm{C}$ at a rate of $3^{\circ} \mathrm{C} / \mathrm{min}$. The complex tensile modulus $E^{*}$, the storage, $E^{\prime}$, and the loss, $E^{\prime \prime}$, modulus, as well as their ratio $\left(E^{\prime \prime} \mid E^{\prime}\right)$, i.e. $\tan \delta$, were recorded for three samples per blend.

\subsection{Scanning electron microscopy (SEM)}

Surface topography of untreated and treated fibres bundles were observed with a Quanta 200 FEG (FEI Company) in environmental mode at an acceleration voltage of $3 \mathrm{keV}$ and a pressure of 0.6-0.8 Torr. The fibre surfaces were sputter coated with carbon to avoid any degradation during observation.

Failure mechanisms were characterized by two methods: (a) the fracture surfaces of the samples were observed after tensile and Charpy impact tests, (b) the SEM was equipped with an in situ tensile apparatus (DEBEN microtest, maximum load $5 \mathrm{kN}$ ) and direct observations of the crack propagation were done at a displacement speed of $0.1 \mathrm{~mm} / \mathrm{min}$ on notched specimens with dimension of $40 \mathrm{~mm} \times 10 \mathrm{~mm} \times 4 \mathrm{~mm}$ and a notch of $4 \mathrm{~mm}$ depth and $45 \pm 1^{\circ}$ opening. Experiments were conducted on three samples per blend. The acceleration voltage was $12.5-15 \mathrm{keV}$ and the pressure was 0.6-0.8 Torr.

\section{Results and discussion}

\subsection{Surface characterization of unmodified and modified fibre bundles}

\subsubsection{FTIR analysis}

Flax fibre bundles are made of tens of elementary fibres (cells) of 5-35 $\mu \mathrm{m}$ in diameter, fibre cells themselves being composed of several concentric layers made of cellulose macromolecules arranged in microfibrils and embedded in a matrix of lignin, pectins (rhamnogalacturonan I and other uronic acids), hemicelluloses (xylan, glucomannan and xyloglucan), and glycine-rich proteins (Morvan et al., 2003). Numerous free and reactive hydroxyl, phenolic and acidic groups as well as non-reactive acetylated groups arise at the surface of fibre bundles. Hydroxyl, phenolic and acidic groups are potentially substitutable with reactive molecules. As assumed by several authors (Abdelmouleh et al., 2002, 2004; Belgacem and Gandini, 2005; Bledzki and Gassan, 1999; Xie et al., 2010), hydrolyzed organosilanes, i.e. silanols $-\mathrm{Si}-\mathrm{OH}$, can be adsorbed on fibre surface while self-condensing in polysiloxanes, and could be grafted on it to a measurable extent after an appropriate heat treatment. Abdelmouleh et al. (2002, 2004, 2007) used a curing temperature of $120^{\circ} \mathrm{C}$ under nitrogen conditions to guarantee an effective chemical bonding of the silane onto the cellulose surface. In their review on cellulose surface modifications, Belgacem and Gandini (2005) assumed that a temperature above $70^{\circ} \mathrm{C}$ is required so that the grafting takes place at detectable rates. This reaction produces $\mathrm{Si}-\mathrm{O}-\mathrm{C}$ and $\mathrm{Si}-\mathrm{O}-\mathrm{Si}$ bonds, but also adsorbed but non-grafted $\mathrm{Si}-\mathrm{OH}$ groups and residual unhydrolyzed $\mathrm{Si}-\mathrm{OCH}_{3}$ groups that can be identified by FTIR analysis (Abdelmouleh et al., 2004; Valadez-Gonzalez et al., 1999b). According to the authors, the asymmetric stretching of $\mathrm{Si}-\mathrm{O}-\mathrm{C}$ and $\mathrm{Si}-\mathrm{O}-\mathrm{Si}$ bonds is attributed to the bands in the range $1200-1140 \mathrm{~cm}^{-1}$. The symmetric stretching of $\mathrm{Si}-\mathrm{O}-\mathrm{C}$ and $\mathrm{Si}-\mathrm{O}-\mathrm{Si}$ bonds can be also detected with the peaks at $1370 \mathrm{~cm}^{-1}$ and $965 \mathrm{~cm}^{-1}$ and near 700 and $1040 \mathrm{~cm}^{-1}$, respectively. Unhydrolyzed $\mathrm{Si}-\mathrm{OCH}_{3}$ groups can be assigned to the peaks in the range 1100 and $1080 \mathrm{~cm}^{-1}$ and the large band around $1015 \mathrm{~cm}^{-1}$ is attributed to $\mathrm{Si}-\mathrm{OH}$ groups. In this study, FTIR analysis (Fig. 3) revealed that all these entities are present on the different treated flax fibre bundles, meaning that full hydrolysis, self-condensation and grafting of silanes was not achieved.

3.1.1.1. Influence of silane concentration. The effect of GPS concentration (1,5 and $10 \mathrm{wt} \%$ for Flax T1, Flax T2 and Flax T3 respectively) was not pronounced, FTIR spectra being very similar (Fig. 3a). This is explained by the fact that the temperature and time of treatments were identical. Self-condensation and grafting of silanols thus occurred in the same conditions and differences cannot be clearly identified by FTIR. The concentrations of silanes used in literature vary widely and ranged from $0.5 \mathrm{wt} \%$ (Kushwaha and Kumar, 2010) to 5 wt\% (Asumani et al., 2012) (fibre weight basis). Abdelmouleh et al. (2002) achieved a comprehensive study with different silane coupling agents adsorbed on microcrystalline cellulose (MCC). The authors found that the maximum concentration of adsorbed silanes to form a monolayer on cellulose surface was 0.24 and $0.91 \mathrm{mmol} / \mathrm{g}$ of MCC, respectively for $\gamma$-methacryloxypropyltrimethoxy silane (MPS) and 3-aminopropyltriethoxy silane (APS), which corresponds to maximum concentration of $5.68 \mathrm{wt} \%$ and $20.1 \mathrm{wt} \%$. The authors also assumed that the nature of the silane coupling agent used can influence the adsorption on cellulose substrate depending of its reactivity. For example $\mathrm{NH}$ or $\mathrm{NH}_{2}$ groups favoured the interaction between the coupling agents and the cellulose substrate. From these results, we can assume that the $5 \mathrm{wt} \%$ and $10 \mathrm{wt} \%$ GPS treatments realized in this study should produce a monolayered polysiloxane network on fibre bundles surfaces.

3.1.1.2. Influence of soaking time. As shown in Fig. $3 \mathrm{~b}$, the soaking time is much more influent on FTIR spectra (Flax T2, Flax T4 and Flax T5). The maximum intensities for the bands assigned to $\mathrm{Si}-\mathrm{O}-\mathrm{C}$ and $\mathrm{Si}-\mathrm{O}-\mathrm{Si}$ bonds were reached for a soaking time of $1 \mathrm{~h}$ (Flax T2). As for the concentration, soaking of the fibres in silane solutions was achieved at very different times in literature, varying from $5 \mathrm{~min}$ (Rong et al., 2001) to $24 \mathrm{~h}$ (Yu et al., 2010). Short times (Flax T4 - 5 min) seem not sufficient for the GPS molecules to be adsorbed on the fibre surface. On the contrary, too long soaking times (Flax T5 $-24 \mathrm{~h}$ ) could favour the hydrolysis of the hydrogen bonds formed between silanols and hydroxyl groups as well as the hydrolysis of the oligosaccharides present at the fibre surface, thus debonding the polysiloxane networks coated on the fibre bundles. Abdelmouleh et al. $(2002,2004)$ found that the adsorption equilibrium on MCC is reached after 1 and $2 \mathrm{~h}$ of soaking for $\gamma$-phenyl-aminopropyltrimethoxy silane (PAPS) and MPS, respectively.

3.1.1.3. Influence of bath and curing temperature. As discussed above, the curing temperature is a critical parameter for the efficient grafting of silanes. Temperatures of curing reported in literature vary from $45^{\circ} \mathrm{C}$ (Asumani et al., 2012) to $120^{\circ} \mathrm{C}$ (Abdelmouleh et al., 2002, 2004, 2007). As shown in Fig. 3c, the flax bundles sample cured at $60^{\circ} \mathrm{C}$ (Flax T6) exhibited the lowest band intensities for $\mathrm{Si}-\mathrm{O}-\mathrm{C}$ and $\mathrm{Si}-\mathrm{O}-\mathrm{Si}$ bonds, meaning that 

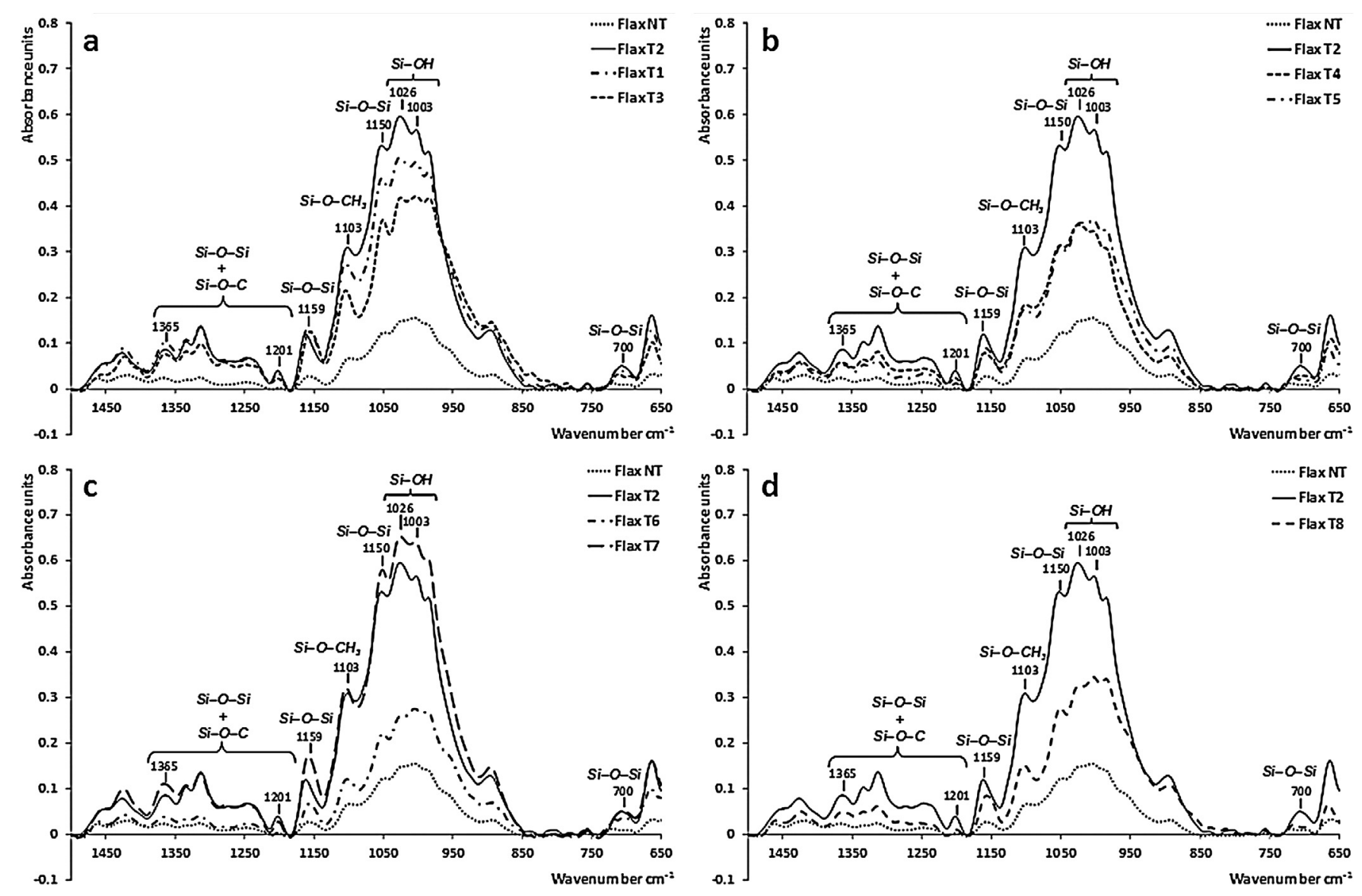

Fig. 3. FTIR spectra of untreated and treated fibre bundles. (a) Influence of silane concentration, (b) influence of soaking time, (c) influence of curing conditions, (d) influence of an alkaline pre-treatment.

condensation and grafting were not efficient in these conditions. This confirms the necessity to use curing temperatures above $105^{\circ} \mathrm{C}$ as proved by Abdelmouleh et al. $(2002,2004)$ in the case of MCC and other pure cellulose substrates. Another interesting parameter is the temperature of the reaction bath. In the case of glass fibres, the adsorption and grafting of silanes take place at very high temperatures that means just below the glass melting temperature. To the best of our knowledge, no results were reported up to now on the influence of the reaction bath temperature on grafting efficiency. As shown in Fig. 3c, heating the bath at $70^{\circ} \mathrm{C}$ (Flax T7) upon the adsorption phase favoured the reactivity between silanols and hydroxyl groups of fibre bundles and led to the highest band intensities for $\mathrm{Si}-\mathrm{O}-\mathrm{C}$ and $\mathrm{Si}-\mathrm{O}-\mathrm{Si}$ bonds. However, it has to be noticed that temperature activates the self-condensation of silanols (Brochier Salon et al., 2008). If occurring too early upon the adsorption phase, it would decrease the number of silanols that are available to be adsorbed on fibre surface by forming, in the solution, polysiloxane networks with limited molecular mobility. This parameter must be thus controlled with care.

3.1.1.4. Influence of an alkaline pre-treatment. The treatment of cellulose fibres with an alkaline solution is known to promote a partial removal of hemicelluloses, pectins, waxes, and lignin present on the fibre surface. This leads to changes in their morphology and chemical composition. Valadez-Gonzalez et al. (1999a) assumed that: (i) it increases the surface roughness that results in a better mechanical interlocking, and (ii) it also enhances the amount of cellulose hydroxyls exposed on the fibre surface, thus increasing the number of possible reaction sites for silanols and other potential grafted molecules. This last point is controversial in literature.
In their comprehensive review on surface modification of cellulose fibres, Belgacem and Gandini (2005) reported that silanes better react with different lignin substrates because of the much more pronounced acidic character of their phenolic hydroxyl groups as compared to hydroxyl groups of cellulose (Castellano et al., 2004). In the present study, alkaline pre-treatment (Flax T8) appears to have a rather negative influence since the bands attributed to $\mathrm{Si}-\mathrm{O}-\mathrm{C}$ and $\mathrm{Si}-\mathrm{O}-\mathrm{Si}$ bonds are much less pronounced (Fig. 3d).

\subsubsection{Wettability}

To complete the qualitative FTIR analysis, the effect of the treatment parameters on the wettability towards ethanol of the different treated fibre bundles was investigated. The GPS grafted at the surface of the treated fibre bundles should decrease their hydrophilic character and hence their wettability, because epoxy functions are less polar than hydroxyl and acidic groups. This decrease of wettability should be function of the degree of selfcondensation and grafting of GPS molecules on the fibre surface, a lowest wettability corresponding to a highest number of GPS grafted. As shown in Fig. 4, $C \cos \theta$ values are decreased up to $45 \%$ when fibre bundles are treated. It has to be noticed that the scattering of the $C \cos \theta$ values remain low, thus supporting the accuracy of this measurement method.

As found from the FTIR analyzes, the GPS concentration in the solution (Flax T1, Flax T2 and Flax T3) does not significantly modify the surface properties. A GPS concentration of $1 \mathrm{wt} \%$ should be too low to allow a complete reaction of all reactive groups present on the fibre surface. A GPS concentration of $5 \mathrm{wt} \%$ appears to be a good compromise in our study. 


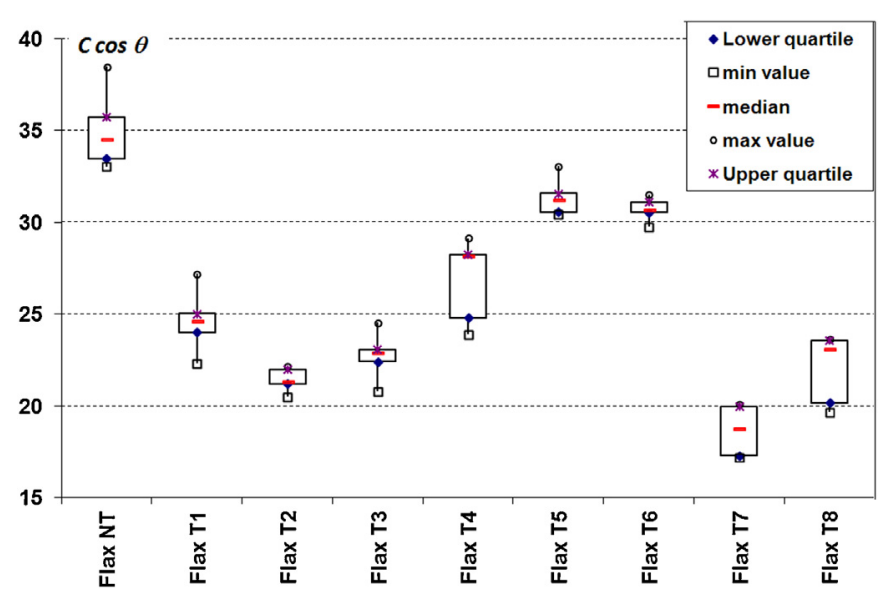

Fig. 4. Wettability towards ethanol of untreated and treated fibre bundles as defined by $C \cos \theta$ values measured by capillary rise.

Concerning the soaking time, our measurements show that this parameter could control significantly the efficiency of the treatment. The lowest wettability was found for $1 \mathrm{~h}$ of soaking (Flax T2) which correlates well with the assumptions and the results obtained from the FTIR analyzes.

As discussed previously, the heating temperature is also a key parameter. It was found that the sample cured at the highest temperature $\left(105^{\circ} \mathrm{C}\right.$ for Flax T2 as compared to $60^{\circ} \mathrm{C}$ for Flax T6) presents a lower wettability. Also, heating the bath at $70^{\circ} \mathrm{C}$ (Flax T7) led to the lowest wettability and thus to an efficient selfcondensation and grafting of silanols on fibre surface as expected from FTIR analyses.

A negative influence of the alkaline pre-treatment was observed, the wettability of the Flax T8 being higher compared to Flax T2. As assumed from the FTIR analyzes, the grafting of GPS molecules could be less efficient due to a lowest reactivity of fibre surface after the alkaline treatment. The decrease of wettability with the grafted GPS molecules could also be counterbalanced by the increase surface tension of the alkaline treated fibres (Doan et al., 2012) due to the removal of hydrophobic components from the surface. The influence of the alkaline pre-treatment on the efficiency of GPS grafting is thus difficult to depict from the wettability measurements but the results show that it does not contribute to increase the hydrophobicity of the fibre bundles.

To conclude, FTIR analysis and wettability measurements are two complementary methods that were successfully used to characterize and compare the efficiency of the different conditions of GPS treatments applied on flax fibre bundles. Significant differences were observed and the best treatment conditions were obtained with Flax T7 > Flax T8 > Flax T2. These results correlate with previous studies performed on pure cellulose substrates (Abdelmouleh et al., 2002, 2004) Therefore, Flax T7 and Flax T8 fibre samples were chosen for PLA reinforced biocomposites and compared to Flax NT fibre sample in the following sections.

\subsection{Mechanical properties of the biocomposites}

Tensile properties have been evaluated for neat PLA and PLA/flax biocomposites. For the neat PLA 7000D, a yield stress with a short plastic region was observed and the elongation at break was $5.6 \%$ in average. For the PLA/flax biocomposites, the breakage occurred with no plastic region and the elongations at break did not exceed $2.6 \%, 3.5 \%$ and $3.8 \%$ in average for PLA/20 wt\% Flax NT, Flax T7 and Flax T8 respectively, thus revealing a brittle behaviour. As shown in Fig. 5a, Young modulus increases significantly by $56 \%$ when incorporating $20 \mathrm{wt} \%$ of non-treated fibres. In a less extent, an additional
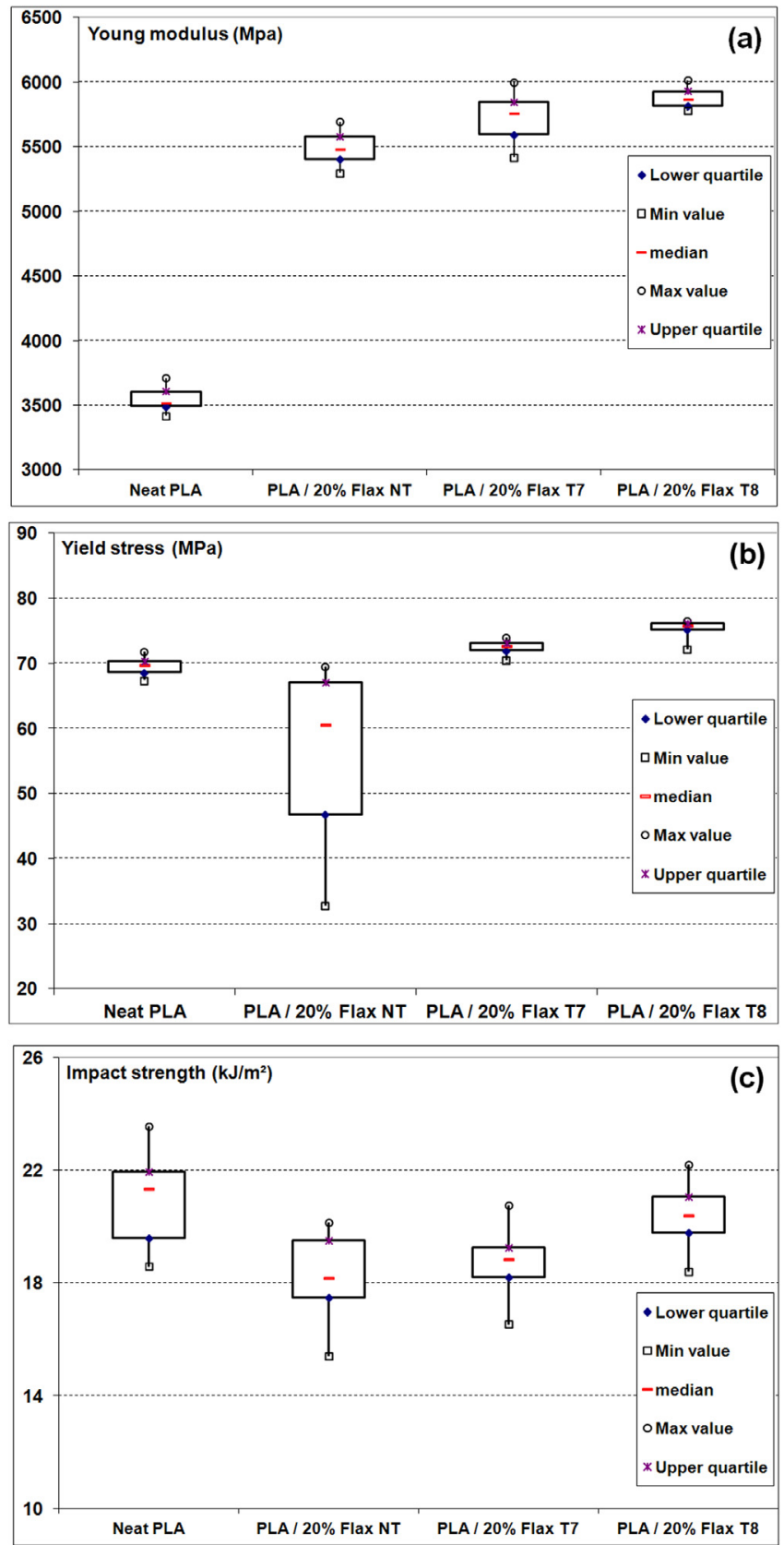

Fig. 5. (a) Young modulus, (b) yield stress and (c) impact strength of neat PLA and PLA/flax biocomposites.

increase is obtained due to the alkaline and GPS treatments ( $+64 \%$ for PLA/20 wt\% Flax T7 and $+67 \%$ for PLA/20 wt\% Flax T8). As will be demonstrated in the following, this has to be related with the creation of a stronger interphase and the significant specific surface area developed by the $20 \mathrm{wt} \%$ fibres. It has to be noticed that the scattering of the results is low which indicates the quality and the reproducibility of the tested specimens.

The ultimate properties of biocomposites are also very sensitive to interface modifications. As shown in Fig. $5 \mathrm{~b}$ and c, the incorporation of $20 \mathrm{wt} \%$ non-treated fibres leads to a drastic decrease of the yield stress and the impact strength as compared to the neat PLA, $-13 \%$ and $-15 \%$ respectively. Moreover, the scattering of the ultimate tensile strength is largely increased. A poor interface between the fibres and the matrix favours the formation and the propagation of cracks that can lead to an early breakage of the specimens at lower elongation at break. On the opposite, biocomposites 
Table 3

Mechanical properties variations of biocomposites as compared to neat PLA and PLA/20 wt\% Flax NT.

\begin{tabular}{|c|c|c|c|c|}
\hline \multirow[t]{2}{*}{ Biocomposites } & \multicolumn{2}{|c|}{ Comparison with neat PLA } & \multicolumn{2}{|c|}{ Comparison with PLA/20\% Flax NT } \\
\hline & Yield stress & Impact strength & Yield stress & Impact strength \\
\hline PLA/20\% Flax NT & $-13 \%$ & $-15 \%$ & - & - \\
\hline PLA/20\% Flax T7 & $+4.5 \%$ & $-12 \%$ & $+20 \%$ & $+4 \%$ \\
\hline PLA/20\% Flax T8 & $+9 \%$ & $-4.5 \%$ & $+25 \%$ & $+12 \%$ \\
\hline
\end{tabular}

reinforced with 20 wt\% Flax T7 and Flax T8 stabilize or even improve the matrix properties and reduce drastically the scattering of the results which indicates that the treatments lead to a better load transfer and a homogenization of the biocomposites microstructure, i.e. a better continuity and stronger interface between the matrix and the fibres. The variations of the average yield stresses and impact strengths of treated biocomposites compared to neat PLA and to PLA/20 wt\% Flax NT are summarized in Table 3.

The overall mechanical properties of biocomposites are thus greatly enhanced by the GPS treatment and the combined alkaline pre-treatment +GPS treatment. It has to be pointed out that the PLA/20\% Flax T8 composite always exhibits higher mechanical performances than PLA/20\% Flax T7, although surface modification analyzes (FTIR and wettability) revealed that Flax T8 fibre bundles could be less GPS grafted than Flax T7. It is thus interesting to investigate the origin of the reinforcement observed and to better understand the physical and chemical phenomena occurring at the fibre/matrix interface for the different biocomposites produced.

\subsection{Characterization of the modifications at the fibre/matrix interface}

The quality of the interface in fibre reinforced composites is governed by two main mechanisms: (i) the mechanical interlocking that is related to the topography of the fibres and the surface tension of both matrix and fibres; (ii) the chemical coupling that is related to the potential chemical interactions that may occur between the fibres surface, the macromolecular chains of the matrix, and the coupling agent used. When modifying fibres to improve the interface, several phenomena can occur at the same time. As cited above, modifications of the topography and of the surface tension and the involving of chemical reactions may occur, but also structural modifications of the fibres as well as the formation of a transcrystalline zone at the interface (Ning et al., 2012). The choice of the characterization methods to investigate the modifications at the interphase, i.e. the transition zone between the fibres and the matrix, is a critical point since it is not easily accessible and can in major cases only be characterized by non-direct methods.

Another critical issue when working with natural fibres is the relative heterogeneity of the treatments. Besides the inhomogeneous reactivity of the fibres with the coupling agents, fibres are usually treated as received, i.e. in the form of bundles, and then separate and break during extrusion and injection processing due to shearing. They become smaller bundles and elementary fibres with an enhanced specific surface. In particular, it has been shown that flax fibres easily separate in elementary fibres probably due to their low lignin content (Le Moigne et al., 2011; Oksman et al., 2009). This was confirmed in this study by the fibre size and shape analysis (Fig. 2), in which only elementary fibres and particles were observed. Consequently, only a limited surface of the fibres exposed to the matrix within the composite is effectively modified during the treatments, as illustrated in Fig. 6. In this example, the amount of treated fibres surface exposed to the matrix after processing would be only $35 \%$ (perimeter of the bundle to the total perimeter of all the elementary fibres), thereby reduces by roughly three times the efficiency of the treatments. For a fibre bundle of $240 \pm 150 \mu \mathrm{m}$ in diameter as those used in this study, this value would be roughly
$11 \pm 7 \%$ (considering a bundle with a simple square section and an average elementary fibre diameter of $20 \mu \mathrm{m}$ ). The larger are the fibre bundles, the least efficient would be the treatment. This highlights the necessity for the fibre producers to individualize fibre bundles into elementary fibres as much as possible during the extraction phases prior any further processing.

\subsubsection{Influence of the surface treatments on the crystal structure of PLA and flax fibres}

Incorporating natural fibres in the PLA matrix can be responsible for modifications in its crystallization by playing the role of nucleating agents. As shown by Wang et al. (2011), sisal fibres have a nucleating ability to transcrystallize the PLA matrix. When placed under isothermal crystallization conditions between 123 and $130^{\circ} \mathrm{C}$, first nuclei appeared preferentially along the fibre axis. The appearance of interfacial crystallization can enhance the mechanical performances in composites due to increase load transfer efficiency (Ning et al., 2012).

In the present study, thermograms of Fig. 7 show that cold crystallization then melting occur during heating. The crystallinity calculated from Eq. (2) was roughly zero for all the samples. The melting enthalpy is indeed equivalent to the enthalpy of cold crystallization and the PLA matrix is thus fully amorphous in all the biocomposites after injection. This is explained by the slow kinetics of crystallization of PLA and the fast cooling during injection which
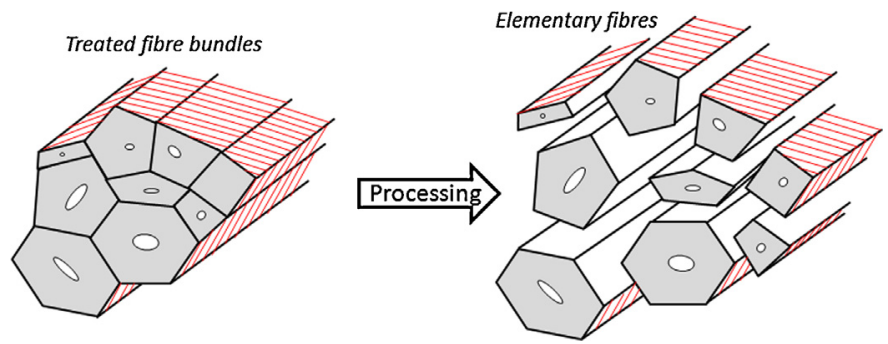

Fig. 6. Illustration of treated fibre surfaces (dashed zones) before processing and the ones exposed to the matrix after extrusion and injection.

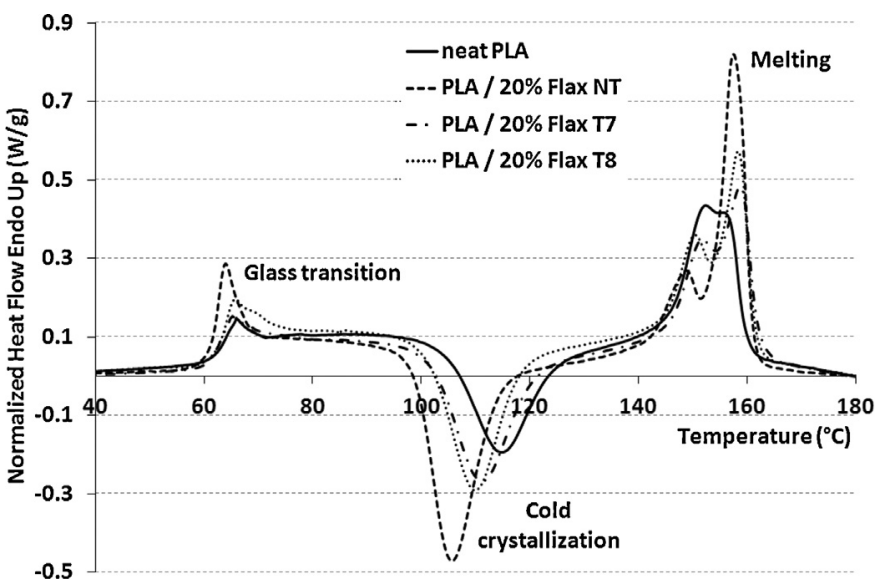

Fig. 7. DSC thermograms of neat PLA and biocomposites recorded at a heating rate of $10^{\circ} \mathrm{C} / \mathrm{min}$ and normalized to PLA amount 


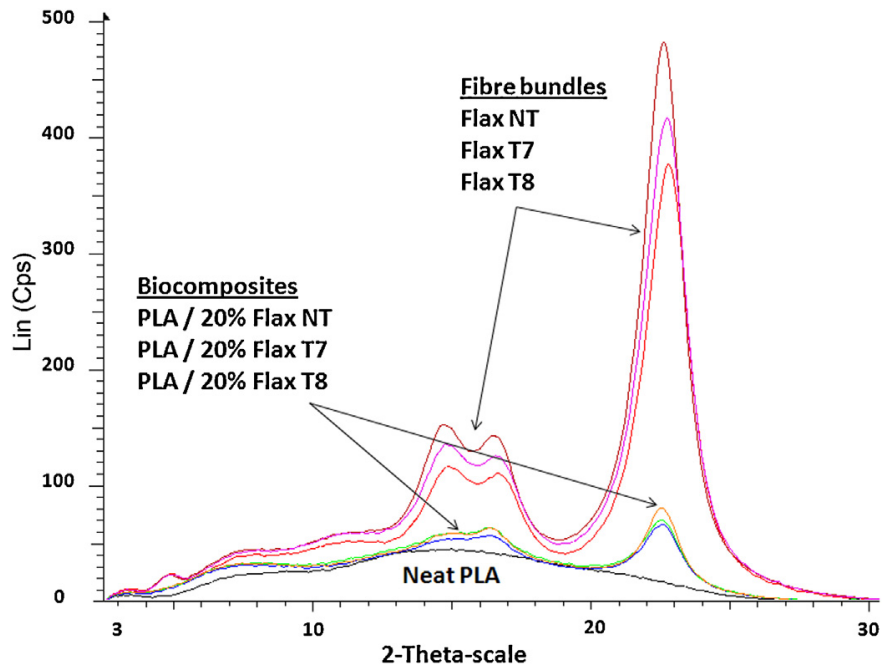

Fig. 8. X-ray diffractograms of flax fibre samples, neat PLA and the corresponding biocomposites.

freezes the matrix before any crystallization has taken place. The diffractograms of Fig. 8 confirm these results. No new crystalline structure is observed in the biocomposites and only the diffraction peaks related to the flax fibres are visible. Crystalline PLA indeed had intense peaks at $2 \theta$ values around $17^{\circ}$ and $19^{\circ}$ that are not visible on the diffractograms. It can also be noticed that the alkaline pre-treatment and GPS treatment did not induce changes in the crystalline structure of flax fibres. The $\mathrm{NaOH}$ concentration ( $5 \%$, $\mathrm{w} / \mathrm{w}$ ) is indeed too low to induce such structural modifications, as a cellulose I-cellulose II transition.

It is interesting to note a graduation in the cold crystallization phenomenon (Fig. 7). The untreated fibres leads to the earliest and the most pronounced cold crystallization $\left(105.6 \pm 0.1^{\circ} \mathrm{C}\right.$, $-35.4 \pm 1.3 \mathrm{~J} / \mathrm{g}$ ), the treated Flax T7 and T8 being intermediate cases $\left(111.1 \pm 1.1^{\circ} \mathrm{C}\right.$ and $109.9 \pm 1.25^{\circ} \mathrm{C},-27.0 \pm 0.5 \mathrm{~J} / \mathrm{g}$ and $-28.3 \pm 1.2 \mathrm{~J} / \mathrm{g}$ respectively) with the pure PLA matrix $\left(114.7 \pm 0.25^{\circ} \mathrm{C},-22.4 \pm 0.3 \mathrm{~J} / \mathrm{g}\right)$. This indicates that untreated flax fibres are nucleating agents and better promote cold crystallization upon heating at their surface than alkaline treated and GPS grafted flax fibres where PLA chains should be entangled and covalently bonded over the surface and thus less mobile. This is also confirmed by the slightly higher glass transition temperature recorded for treated fibres $\left(T_{\mathrm{g}}\right.$ of $62.1 \pm 0.61^{\circ} \mathrm{C}$ and $62.8 \pm 0.58^{\circ} \mathrm{C}$ for Flax T7 and T8 respectively versus $60.8 \pm 0.25^{\circ} \mathrm{C}$ for Flax NT) which could be related to immobilized PLA chains at their surface. These results are in contrast with the study of Wang et al. (2011) related to sisal/PLA biocomposites in which the fibre surface modification by using alkali or aminosilanes (APS) had little or no influence on the nucleation ability of sisal fibres. This could be explained by weaker interactions between PLA and APS as compared to GPS.

To conclude, no significant modifications in the microstructure of PLA and flax fibres (crystallinity, size and shape distribution) were observed after treatments and processing, and the increased mechanical performances of PLA/20\% Flax T7 and T8 as compared to PLA/20\% Flax NT thus mainly originate from the interfacial phenomenon brought by the alkaline pre-treatment and the GPS treatment. It has to be noticed that upon re-heating in the DSC experiments, the nucleation ability of the fibres is decreased by the alkaline and GPS treatments.

\subsubsection{Influence of the surface treatments on the viscoelastic} behaviour of the biocomposites

The decoupling of the elastic (storage modulus $E^{\prime}$ ) and the viscous (loss modulus $E^{\prime \prime}$ ) response of the material allows to quantify

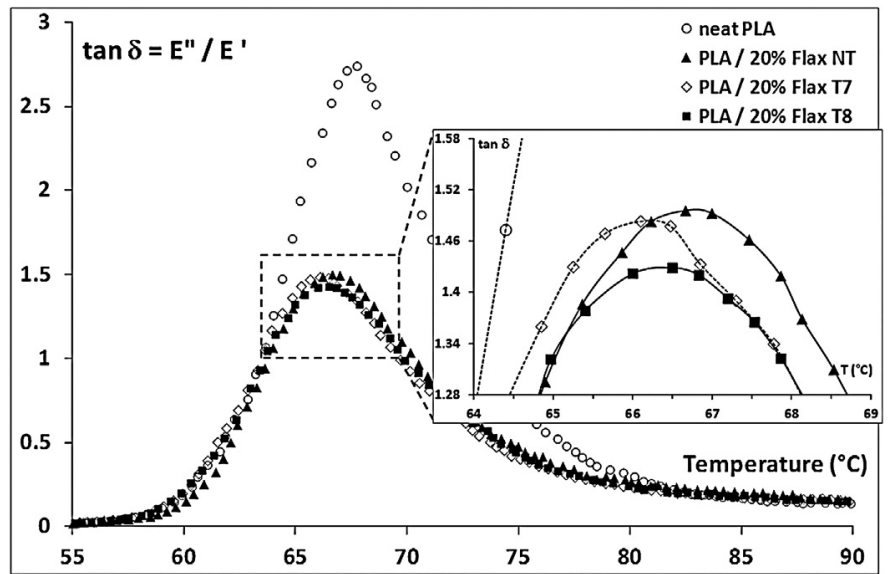

Fig. 9. Damping at the $\alpha$ transition from $55^{\circ} \mathrm{C}$ to $90^{\circ} \mathrm{C}$ for neat PLA and biocomposites. Each curve is an average of three experiments.

the damping $\left(\tan \delta=E^{\prime \prime} \mid E^{\prime}\right)$ which is a sensitive indicator of molecular motions and relaxations. In a composite, the molecular motions at the interfacial region contribute to the damping in addition to those of the matrix and the fibres. The analysis of the damping thus enables to quantify the interface bonding (Dong and Gauvin, 1993). It has been demonstrated that the behaviour of composites at the fibre/matrix interface is better detected in flexural deformation as fibres carried more load, especially in the case of unidirectional composites (Dong and Gauvin, 1993; Gerard et al., 1986, 1990; Reed, 1980).

The maximum damping for a polymer is reached at the $\alpha$ transition which is related to the glass transition of its amorphous region. DSC and X-ray experiments revealed that the PLA matrix was always amorphous in the injected specimens. As a consequence, the damping magnitude was particularly high (up to 2.749 for the neat matrix) for all the samples. As shown in Fig. 9, incorporating $20 \mathrm{wt} \%$ of non-treated flax fibres in the PLA matrix leads to a strong decrease of the damping from $2.749 \pm 0.002$ to $1.505 \pm 0.007$ ( $45 \%$ of decrease) related to the elastic response of the fibres. In the case of an ideal composite for which the interfaces simply play their role of transferring load and do not contribute to damping, Nielsen and Landel (1974) suggested that the damping of the composites $\tan \delta_{c}^{0}$ can be estimated from the mixing rule (Eq. (3)):

$\tan \delta_{c}^{0}=\left(1-V_{f}\right) \tan \delta_{m}$

where $V_{f}$ is the volume fraction of fibres, $\tan \delta_{m}$ the damping of the matrix and considering a low damping reinforcement.

Considering this equation, the damping of the biocomposites should be 2.25 which is much higher than the damping measured: $1.505 \pm 0.007,1.491 \pm 0.066$ and $1.441 \pm 0.009$ for PLA/20\% Flax NT, PLA/20\% Flax T7 and PLA/20\% Flax T8, respectively. This indicates that, for all biocomposites, strong interactions occur at the interfaces and tend to reduce the damping due to the significant specific surface area between the fibres and the matrix and the formation of an interphase with reduced molecular mobility. The effect of such an interphase on the damping was described by Ziegel and Romanov (1973) by the following equation:

$\tan \delta_{c}^{0}=\left(1-B V_{f}\right) \tan \delta_{m}$

where $B$ is a parameter that correct the volume fraction of fibres because of the formation of a strong interphase.

The stronger the interfacial interactions, the thicker the immobilized layer and the higher the value of parameter $B$ (Dong and Gauvin, 1993). Fig. 10 gives the minimum and maximum values of parameter $B$ calculated from the minimum and maximum damping values of the different biocomposites. It is shown that 


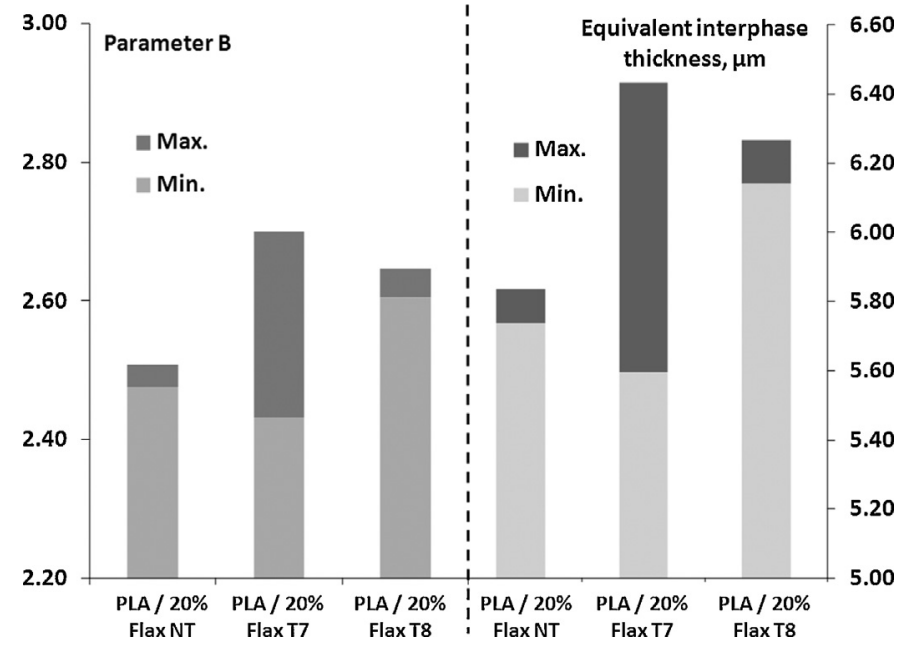

Fig. 10. Values of parameter $B$ from Eq. (4) and calculated equivalent interphase thickness for the different biocomposites.

even with non-treated fibres, the parameter $B$ is high and that interactions naturally occur between flax fibres and PLA, possibly through Van der Walls and hydrogen bonding as postulated by Raj et al. (2011). The damping is lowered of 0.014 and 0.064 for PLA/20\% Flax T7 and PLA/20\% Flax T8, respectively, the parameter $B$ and hence the specific surface area being in turn higher. This is representative of enhanced chemical coupling and mechanical interlocking at the interface due to the alkaline pre-treatment and/or the GPS treatment. This result is also consistent with the increased stiffness measured for the treated biocomposites. It is also interesting to note that the damping curves are unsymmetrical, the decrease of damping compared to the neat matrix being more pronounced above $67^{\circ} \mathrm{C}$. It indicates that this is mostly the long PLA chains that are entangled and bonded over the surface and thus less mobile. It has to be noticed that the shift of glass transition of almost $2{ }^{\circ} \mathrm{C}$ observed in DSC (Section 3.3.1) was not correlated with a significant shift of the $\alpha$ transition or the peak of loss modulus (less than $1^{\circ} \mathrm{C}$ ) in DMTA. A decrease of damping of about 0.025 was observed by Abdelmouleh et al. (2007) with LDPE composites reinforced with $25 \mathrm{wt} \%$ cellulose fibres treated with $\gamma$-mercaptopropytrimethoxylsilane (MRPS). Huda et al. (2008) observed a decrease of damping also accompanied by a shift of the glass transition with laminated composites made of PLA and $40 \mathrm{wt} \%$ kenaf fibres treated with APS. It should be emphasized that microstructural aspects as the orientation of the fibres within the injected sample may influence the results. Research works are in progress to better characterize the orientation of natural fibres in thermoplastic composites (Bourmaud et al., 2013) and should provide meaningful information to better depict the interfacial phenomena in natural fibres reinforced composites.

Based on the values of parameter B and considering an elementary fibre of $20 \mu \mathrm{m}$ in diameter, it is possible to calculate an equivalent thickness of interphase. The calculation gives average equivalent interphase thickness of 5.74-5.84 $\mu \mathrm{m}, 5.60-6.43 \mu \mathrm{m}$ and $6.14-6.27 \mu \mathrm{m}$ for PLA/20\% Flax NT, PLA/20\% Flax T7 and PLA/20\% Flax T8, respectively (Fig. 10). These values are in agreement with those reported in literature for other composites systems based on glass fibres (Bergeret and Krawczak, 2006; Heman, 2008). In reality, the interphase is not homogeneous around all fibres. As evocated above, only a limited surface of the fibre bundles undergoes the alkaline pre-treatment and the GPS treatment (see Fig. 6). The equivalent interphase thickness for PLA/20\% Flax T7 and PLA/20\% Flax T8 is thus an average of interfacial zones of $5.80 \mu \mathrm{m}$ thick in which only PLA/fibres interactions occur, and thicker interfacial zones in which stronger interactions occur thanks to the alkaline pre-treatment and the GPS treatment.
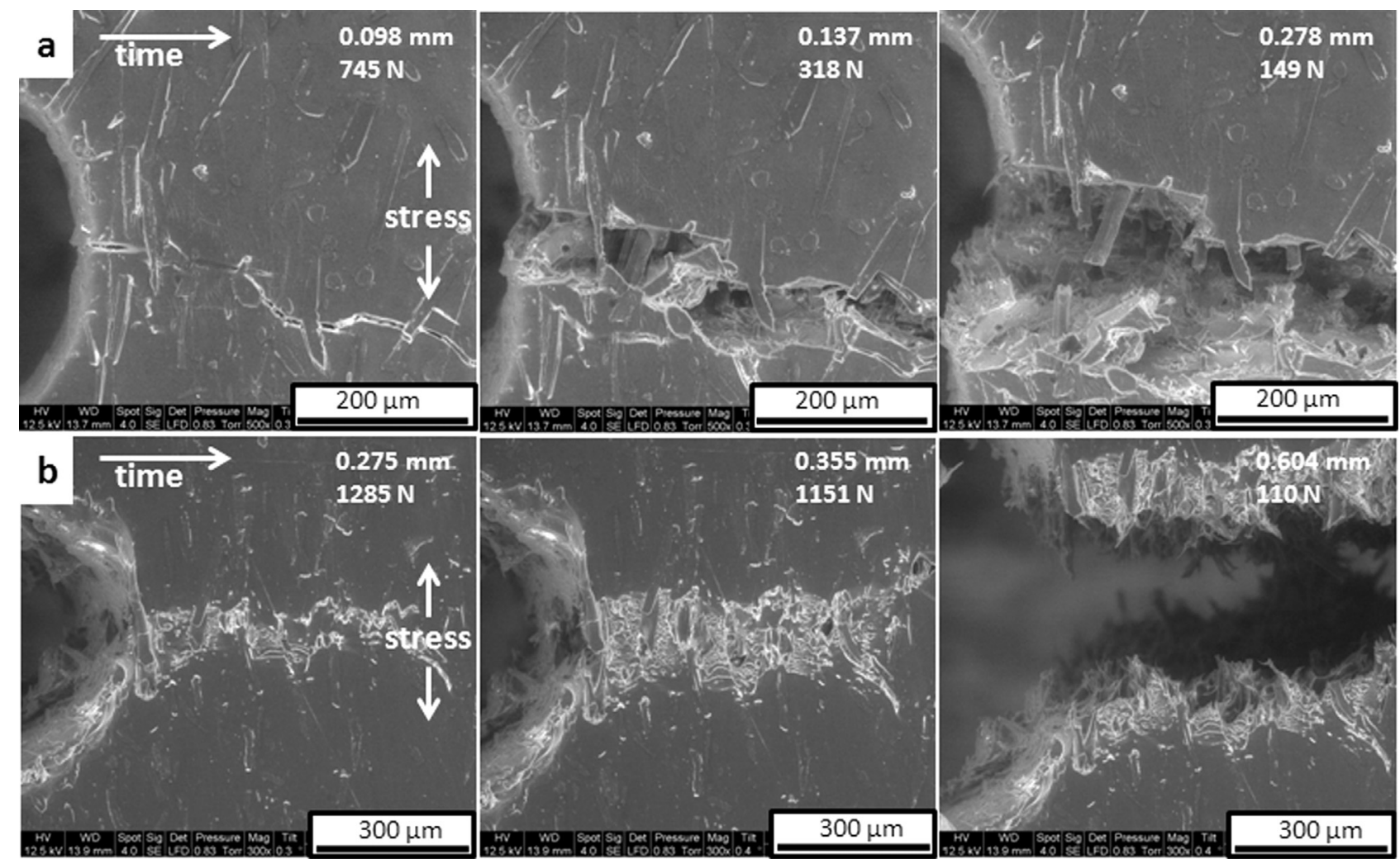

Fig. 11. SEM observations during crack propagation in notched specimens for (a) PLA/20\% Flax NT (see also Video 1) and (b) PLA/20\% Flax T8 (see also Video 2). 


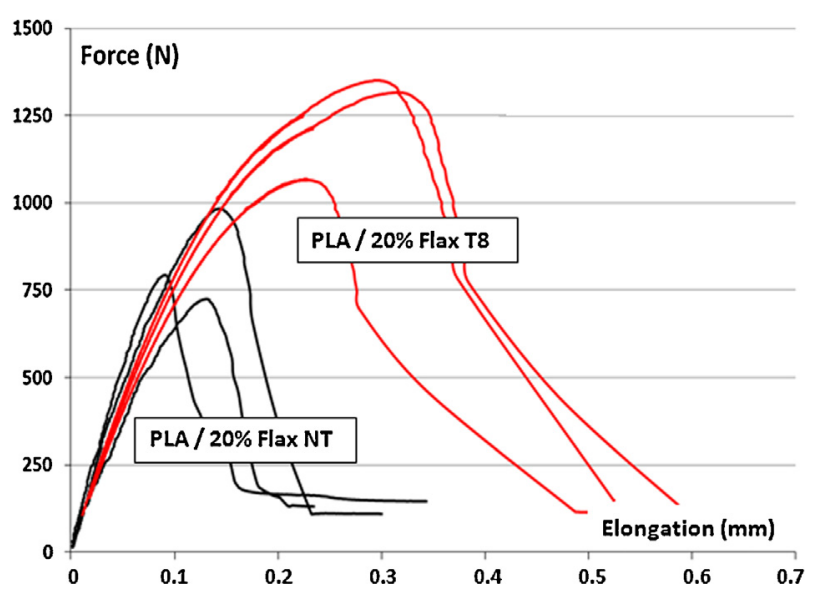

Fig. 12. Loading force versus elongation curves recorded during crack propagation for notched specimens of PLA/20\% Flax NT and PLA/20\% Flax T8 (three tests per biocomposites).

Considering the assumption that only $11 \pm 7 \%$ of the surface of the fibre bundles is treated, it would give approximate equivalent interphase thickness in these strongest interfacial zones of $6.3-8 \mu \mathrm{m}$ and 8-15.8 $\mu \mathrm{m}$ for PLA/20\% Flax T7 and PLA/20\% Flax T8, respectively.

\subsubsection{Influence of the surface treatments on the failure} mechanisms at the fibre/matrix interface

The failure mechanisms have been observed by in situ visualizations of the crack propagation on notched samples. Due to the notched, the breakage of the samples occurs by tearing and is not brittle. This experiment can be assimilated to a pull-out test at a larger scale, i.e. not only one fibre but all the fibres are extracted from the matrix during the crack propagation. As shown in Fig. 11 and Videos 1 and 2, PLA/20\% Flax NT and PLA/20\% Flax T8 composites present very different behaviours during failure. In the case of non-treated Flax NT fibres, the crack occurs by a clear break of the matrix and a debonding of the fibres at the interface which is characteristic of an adhesive interfacial failure (Fig. 11a and Video 1). This result substantiates the large scattering of the yield stress observed for the PLA/Flax NT composite as discussed in Section 3.2. In contrast, the Flax T8 based biocomposite shows a cohesive interfacial failure with a tearing of the matrix and a breaking of the fibres that remain bonded to the matrix (Fig. 11b and Video 2). This is confirmed by the force-elongation curves (Fig. 12) recorded during the experiments. The PLA/20\% Flax NT composite breaks at $830 \pm 125 \mathrm{~N}$ in average with maximum elongation of $0.12 \pm 0.02 \mathrm{~mm}$, while PLA/20\% Flax T8 composite breaks at $1250 \pm 130 \mathrm{~N}$ in average, i.e. $50 \%$ higher, with maximum elongation of $0.28 \pm 0.045 \mathrm{~mm}$, i.e. $133 \%$ higher. The increased area under the curve is representative of a higher tenacity for PLA/20\% Flax T8. It can be noticed that the low tensile speed used $(0.1 \mathrm{~mm} / \mathrm{min})$ in this experiment allows to intensify the interfacial phenomena as compared to the classical tensile tests for which an increase of only $25 \%$ was observed with Flax T8 based biocomposite compared to Flax NT based biocomposite (see Table 3).

Another interesting phenomenon that highlights the cohesive failure observed with treated fibres was the partial peeling of the fibres as illustrated in Fig. 13. This indicates that the interactions occurring at the fibre/matrix interphase, i.e. the bonding with GPS and the fibres/PLA interactions, are stronger that the interactions occurring within the fibre layers, mainly through hydrogen bonding (Morvan et al., 2003). The solvents used for alkaline and silane treatments may also be responsible for the weakening of the fibres and the decohesion of the layers due to the removal of cements as pectins and hemicelluloses. This phenomenon was also observed

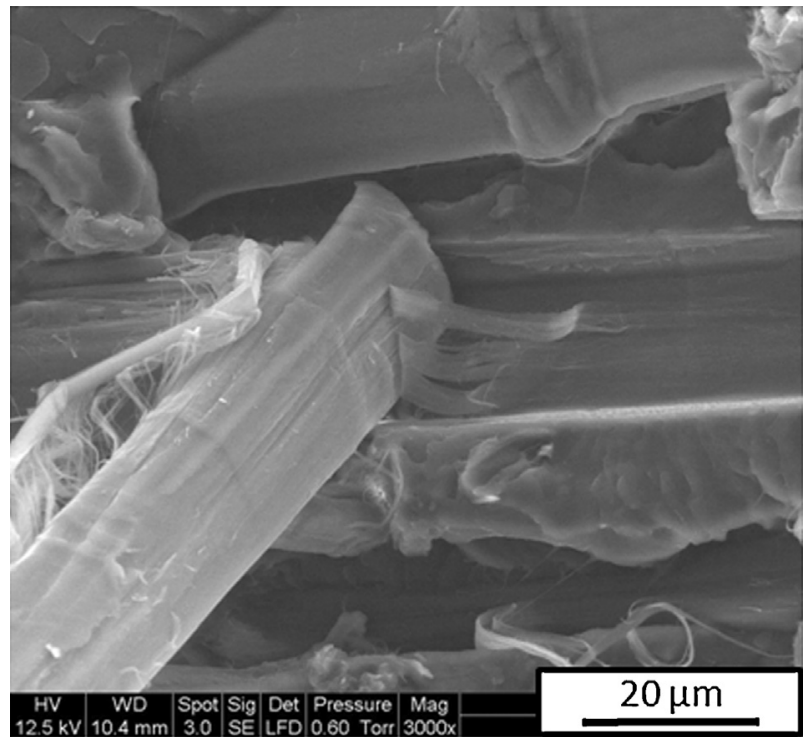

Fig. 13. SEM pictures of a Flax T7 fibre at fracture surface after tensile test.

recently by Le Duigou et al. (2012b) with PLA/flax fibres systems studied with a microdroplet debonding test on single fibre.

The observations of failure mechanisms coupled with the DMA experiments confirm the creation of a strong interphase between the PLA matrix and the flax fibres. The alkaline pre-treatment and the GPS treatment promote the interactions at the interphase that is well illustrated by the cohesive interfacial failure.

\subsection{Proposal of mechanisms at the fibre/matrix interface}

\subsubsection{Chemical coupling}

The grafted GPS molecules are able to react with PLA at the high temperatures reached upon extrusion and injection. A covalent bond can be formed by esterification with the epoxy functions of GPS and the carboxyl end groups of PLA (Bergeret et al., 2004; Yu et al., 2010). GPS molecules should thus promote the covalent bonding of the treated surfaces of flax fibres with the PLA matrix. This creates an interphase made of polysiloxane layers and entangled PLA macromolecules which ensure a gradual transition and a

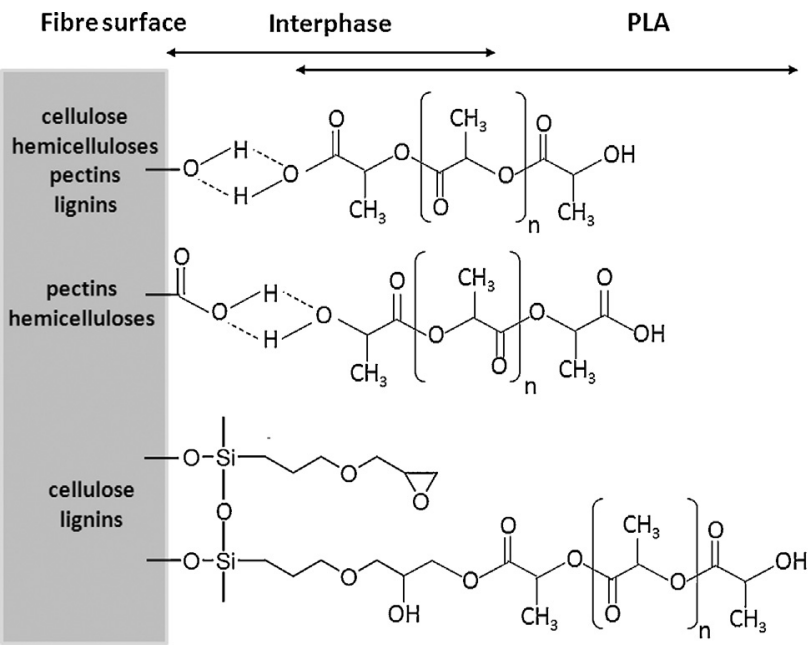

Fig. 14. Schematic illustration of the potential chemical coupling occurring at the interfacial zone: (1a) and (1b) interactions of carboxyl and hydroxyl end groups of PLA through direct Van der Walls and/or hydrogen bonding with free hydroxyl and acidic groups of flax fibres and, (2) esterification reaction with the carboxyl end group of PLA and the epoxy function of GPS grafted on the surface of flax fibres. 

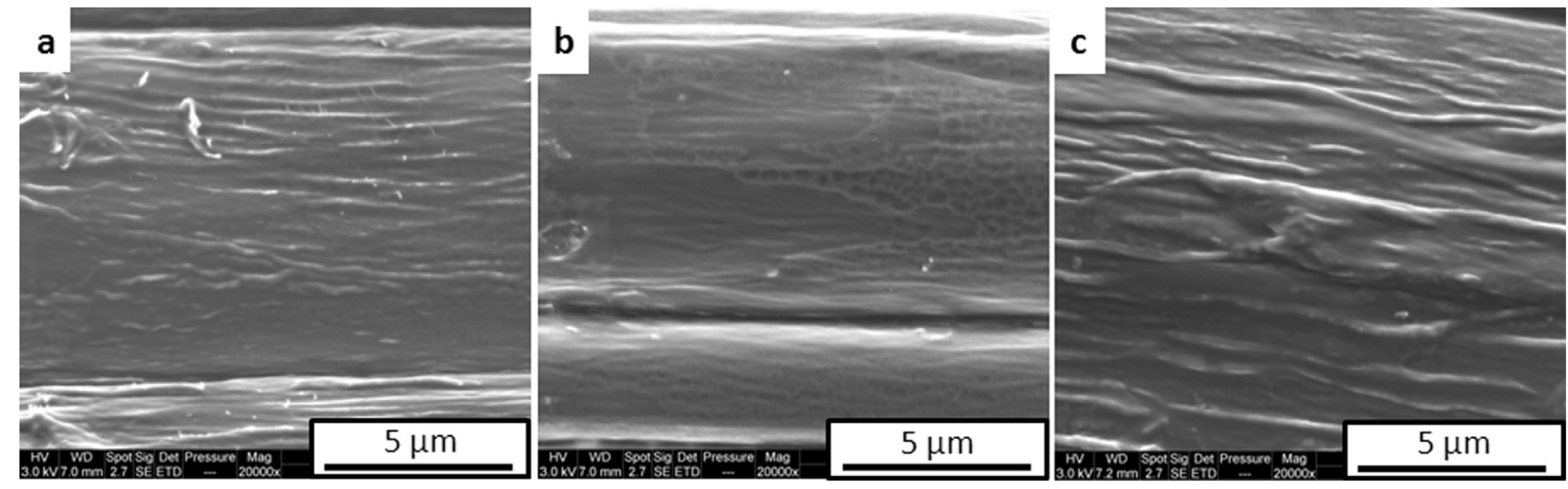

Fig. 15. SEM observations of the surfaces of Flax NT (a), Flax T7 (b) and Flax T8 (c) fibre bundles.

better load transfer between the fibres and the matrix. As outlined above, this interphase should not be homogeneous all around the fibres, a significant fraction of the surfaces exposed to the matrix being not treated with GPS (Fig. 6). Raj et al. (2011) also suggested that direct Van der Waals and/or hydrogen interactions between the hydroxyl groups of cellulose and carboxyl end groups of PLA could enhance the adhesion between flax fibres and PLA. Interactions between carboxyl end groups of PLA and hydroxyl groups of hemicelluloses and pectins and phenolic groups of lignin as well as interactions between hydroxyl end groups of PLA and uronic acids of pectins and hemicelluloses may also be expected.

In the case of non-treated Flax NT fibres, only direct interactions, i.e. Van der Walls and/or hydrogen bonding, between the hydroxyls, the phenolic and the uronic acid groups at the fibre surface and carboxyl and hydroxyl end groups of PLA should occur (reactions (1a) and (1b) in Fig. 14). In the case of Flax T7 fibres, mainly silanes/PLA coupling reaction (reaction (2) in Fig. 14) occur as we showed from wettability and FTIR analyzes that they were the most silane grafted fibres. Flax T8 fibres have less grafted silanes on their surface but also less lignin, hemicelluloses and pectins which were removed by the alkaline pre-treatment. In this last case, the chemical coupling reactions should thus be a combination of direct cellulose hydroxyls/PLA interactions and silanes/PLA interactions (reaction (1a) and reaction (2) in Fig. 14).

\subsubsection{Mechanical interlocking}

The increased hydrophobicity of flax fibres after GPS treatments should also favour the wettability and thus the mechanical interlocking with PLA. However, the biocomposite based on Flax T8 fibres, which were alkaline pre-treated and appeared to be less GPS grafted than Flax T7 fibres, exhibit the highest mechanical performances. The chemical coupling and wettability are thus not the only parameters governing the grafting. The alkaline pre-treatment appears to play an important role in the mechanical behaviour of the biocomposites. It is indeed known to increase surface roughness and to contribute to a better mechanical coupling (Doan et al., 2012; Li et al., 2007; Valadez-Gonzalez et al., 1999a). It has been shown recently from microdroplet debonding experiments on single fibres (Le Duigou et al., 2010a,b, 2012b) that the apparent shear strength at the interface for untreated flax/PLA is more than two times higher than glass fibre/PLA. This was explained by the higher roughness of flax fibres. The authors also showed that cleaning fibres with water can reduce roughness but increase interface strength due to the removal of weakly bonded surface components.

Comparing SEM pictures of flax fibre bundles NT, T7 and T8 (Fig. 15), variations in roughness can be observed. Non-treated fibres (Flax NT) present a grooved surface due to the presence of weakly bonded residues of lignin and pectins from the middle lamellae that probably do not participate to the interface strength. The surface of the bundles is smoothed after GPS treatment (Flax T7). This can be explained by the acidic conditions of the GPS treatment which should have partially removed hemicelluloses, waxes, pectins and lignin from the surface, and the silane coating which should also have partially filled up the pores and interstices. In contrast, the combined "alkaline + GPS" treatment of Flax T8 fibres allow to keep even enhance the grooved aspect of the surface by better removing hemicelluloses, waxes, pectins and lignin from the surface. This should provide a better mechanical interlocking and hence explain the higher mechanical properties of the PLA/20\% Flax T8 biocomposites. It has to be emphasized that the roughness of fibre bundles surfaces are not representative of the overall roughness of the individualized elementary fibres within the composite. As explained previously (Fig. 6), a significant fraction of the fibre surfaces exposed to the matrix is not treated.

\section{Conclusions}

The effect of optimized GPS organosilane treatments on the surface properties of flax fibres and the resulting mechanical properties and interface modifications in flax fibres reinforced poly(lactic acid) (PLA) biocomposites have been studied. It was demonstrated that optimizing the organosilane treatment conditions increases the hydrophobicity of the fibres, and improves significantly the stiffness, the yield stress and the impact strength of the biocomposites, while reducing largely the scattering. The origins of the reinforcement at the fibre/matrix interface were investigated at the macromolecular and the microstructural levels by physico-chemical and mechanical cross-analyses.

The study of the viscoelastic properties of the biocomposites revealed a decrease in damping for treated fibres based biocomposites compared to untreated ones because of the formation of a layer of immobilized macromolecular chains resulting from stronger interactions at the fibre/matrix interface. From these results, equivalent interphase thicknesses have been calculated. Observations of crack propagation by an innovative in situ tensile test performed in a scanning electron microscope illustrated clearly the effect of the optimized treatments on the failure mechanisms. The treated biocomposites showed a cohesive interfacial failure at much higher loads than biocomposites reinforced by untreated flax fibres, which highlights the enhanced load transfer from the PLA matrix to the flax fibres.

We assume that the reinforcement mainly results from both a chemical coupling and a mechanical interlocking occurring at the fibre/matrix interface. Two main mechanisms illustrating the chemical coupling are proposed: (i) direct Van der Walls and/or hydrogen interactions between hydroxyl, phenolic and acidic 
groups at the fibre surface and hydroxyl and carboxyl end groups of PLA and, (ii) esterification reaction between epoxy functions of the GPS coupling agent grafted at the fibre surface and acidic end groups of PLA. Moreover, the results showed that the alkaline pre-treatment used increases the roughness of the fibres and provides a good balance between chemical coupling and mechanical interlocking mechanisms, leading to the highest mechanical performances.

These results open interesting perspectives to better depict the interfacial phenomena in natural fibres based thermoplastic composites and on the potential of organosilanes for the surface treatment of natural fibres. The effect of such treatments on the durability and the end of life (biodegradability, recycling) of natural fibres/PLA composites will be considered in future works. The development of continuous treatment processes is also in progress for an industrial up-scaling.

\section{Acknowledgements}

The authors are indebted to the students that contributed to this work, i.e. J. Cotinat and T. Gherardi.

\section{Appendix A. Supplementary data}

Supplementary material related to this article can be found, in the online version, at http://dx.doi.org/10.1016/j.indcrop. 2013.11.022.

\section{References}

Abdelmouleh, M., Boufi, S., Salah, A.B., Belgacem, M.N., Gandini, A., 2002. Interaction of silane coupling agents with cellulose. Langmuir 18, 3203-3208.

Abdelmouleh, M., Boufi, S., Belgacem, M.N., Duarte, A.P., Salah, A.B., Gandini, A., 2004. Modification of cellulosic fibres with functionalised silanes: development of surface properties. International Journal of Adhesion and Adhesives 24, 43-54.

Abdelmouleh, M., Boufi, S., Belgacem, M.N., Dufresne, A., 2007. Short natural-fibre reinforced polyethylene and natural rubber composites: effect of silane coupling agents and fibres loading. Composites Science and Technology 67, 1627-1639.

AFNOR, 1997. Animal feeding stuffs - determination of sequential cell-wall-method by treatment with neutral and acid detergent and sulfuric acid. NF V 18-122, 11.

AFNOR, 2008. Animal feeding stuffs - determination of acid detergent fibre (ADF) and acid detergent lignin (ADL) contents. NF EN ISO 13906, 18pp.

AFNOR, 2009. Reinforcement fibres - flax fibres for plastics composites - part 2: determination of tensile properties of elementary fibres. XP T 25-501-2, 15.

Asumani, O.M.L., Reid, R.G., Paskaramoorthy, R., 2012. The effects of alkali-silane treatment on the tensile and flexural properties of short fibre non-woven kenaf reinforced polypropylene composites. Composites Part A: Applied Science and Manufacturing 43, 1431-1440.

Baley, C., 2002. Analysis of the flax fibres tensile behaviour and analysis of the tensile stiffness increase. Composites Part A: Applied Science and Manufacturing 33, 939-948.

Belgacem, M.N., Gandini, A., 2005. The surface modification of cellulose fibres for use as reinforcing elements in composite materials. Composite Interfaces 12 , $41-75$.

Bergeret, A., Bozec, M.-P., Quantin, J.-C., Crespy, A., 2004. Study of interphase in glass fiber reinforced poly(butylene terephthalate) composites. Polymer Composites $25,12-25$.

Bergeret, A., Krawczak, P., 2006. Liaison renfort/matrice: définition et caractérisation. Techniques de L'Ingénieur, Plastiques et Composites. AM 5305, 1-19.

Bledzki, A.K., Gassan, J., 1999. Composites reinforced with cellulose based fibres. Progress in Polymer Science 24, 221-274.

Bourmaud, A., Riviere, J., Le Duigou, A., Raj, G., Baley, C., 2009. Investigations of the use of a mussel-inspired compatibilizer to improve the matrix-fiber adhesion of a biocomposite. Polymer Testing 28, 668-672.

Bourmaud, A., Ausias, G., Lebrun, G., Tachonb, M.-L., Baley, C., 2013. Observation of the structure of a composite polypropylene/flax and damage mechanisms under stress. Industrial Crops and Products 43, 225-236.

Brochier Salon, M.-C., Bayle, P., Abdelmouleh, M., Boufi, S., Belgacem, M.N., 2008. Kinetics of hydrolysis and self condensation reactions of silanes by NMR spectroscopy. Colloids and Surfaces A: Physicochemical and Engineering Aspects 312, 83-91.

Cantero, G., Arbelaiz, A., Llano-Ponte, R., Mondragon, I., 2003. Effects of fibre treatment on wettability and mechanical behaviour of flax/polypropylene composites. Composites Science and Technology 63, 1247-1254
Castellano, M., Gandini, A., Fabbri, P., Belgacem, M.N., 2004. Modification of cellulose fibres with organosilanes: under what conditions does coupling occur? Journal of Colloid and Interface Science 273, 505-511.

Chen, F., Liu, L., Cooke, P.H., Hicks, K.B., Zhang, J., 2008. Performance enhancement of poly(lactic acid) and sugar beet pulp composites by improving interfacial adhesion and penetration. Industrial and Engineering Chemistry Research 47, $8667-8675$.

Cho, D., Seo, J.M., Lee, H.S., Cho, C.W., Han, S.O., Park, W.H., 2007. Property improvement of natural fiber-reinforced green composites by water treatment. Advanced Composite Materials 16, 299-314.

Dissanakaye, N., Summerscales, J., Grove, S., Singh, M., 2009. Life cycle assessment of flax fibre for the reinforcement of composites. Journal of Biobased Materials and Bioenergy 3, 1-4

Doan, T.T.L., Brodowsky, H., Mäder, E., 2012. Jute fibre/epoxy composites: surface properties and interfacial adhesion. Composites Science and Technology 72 , $1160-1166$

Dong, S., Gauvin, R., 1993. Application of dynamic mechanical analysis for the study of the interfacial region in carbon fiber/epoxy composite materials. Polymer Composites 14, 414-420.

Faruk, O., Bledzki, A.K., Fink, H.-P., Sain, M., 2012. Biocomposites reinforced with natural fibers: 2000-2010. Progress in Polymer Science 37, 1552-1596.

Fischer, E.W., Sterzel, H.J., Wegner, G., 1973. Investigation of the structure of solution grown crystals of lactide copolymers by means of chemical reactions. Kolloid-Z. U. Z Polymere 251, 980-990.

Gerard, J.F., Hamelin, H., Merle, G., Montel, C., Perret, R., Pillot, C., 1986. Viscoelastic investigation of interfacial damage of glass and carbon fibers composite materials. Polymer Bulletin 16, 559-566.

Gerard, J.F., Andrews, S.J., Macosko, C.W., 1990. Dynamic mechanical measurements: comparison between bending and torsion methods on a graphite-reinforced and a rubber-modified epoxy. Polymer Composites 11, 90-97.

Graupner, N., Herrmann, A.S., Müssig, J., 2009. Natural and man-made cellulose fibrereinforced poly(lactic acid) (PLA) composites: an overview about mechanical characteristics and application areas. Composites Part A: Applied Science and Manufacturing 40, 810-821.

Heman, M.-B., 2008. Contribution to Study of Interphases Behaviour in Hydrothermal Ageing in Thermosetting Matrix/sized Glass Fibres Systems. Université du sud Toulon-Var, France, pp. 121-165 (PhD Dissertation) http://tel.archives-ouvertes.fr/tel-00348059 (chapter 3).

Hu, R., Lim, J.-K., 2007. Fabrication and mechanical properties of completely biodegradable hemp fiber reinforced polylactic acid composites. Journal of Composite Materials 41, 1655-1669.

Huda, M.S., Drzal, L.T., Mohanty, A.K., Misra, M., 2008. Effect of fiber surfacetreatments on the properties of laminated biocomposites from poly(lactic acid) (PLA) and kenaf fibers. Composites Science and Technology 68, 424-432.

Joshi, S.V., Drzal, L.T., Mohanty, A.K., Arora, S., 2004. Are natural fiber composites environmentally superior to glass fiber reinforced composites? Composites Part A: Applied Science and Manufacturing 35, 371-376.

Kalia, S., Kaith, B., Kaur, I., 2009. Pretreatments of natural fibers and their application as reinforcing material in polymer composites-a review. Polymer Engineering and Science 49, 1253-1272.

Kabir, M.M., Wang, H., Lau, K.T., Cardona, F., 2012. Chemical treatments on plantbased natural fibre reinforced polymer composites: an overview. Composites Part B: Engineering 43, 2883-2892.

Kushwaha, P.K., Kumar, R., 2010. Effect of silanes on mechanical properties of bamboo fiber-epoxy composites. Journal of Reinforced Plastics and Composites 29, $718-724$.

Le Duigou, A., Davies, P., Baley, C., 2010a. Interfacial bonding of flax fibre/Poly(Llactide) bio-composites. Composites Science and Technology 70, 231-239.

Le Duigou, A., Davies, P., Baley, C., 2010b. Macroscopic analysis of interfacial properties of flax/PLLA biocomposites. Composites Science and Technology 70, $1612-1620$.

Le Duigou, A., Davies, P., Baley, C., 2011. Environmental impact analysis of the production of flax fibres to be used as composite material reinforcement. Journal of Biobased Materials and Bioenergy 5, 1-13.

Le Duigou, A., Davies, P., Baley, C., 2012a. Replacement of glass/unsaturated polyester composites by flax/PLLA biocomposites: is it justified? Journal of Biobased Materials and Bioenergy 5, 466-482.

Le Duigou, A., Bourmaud, A., Balnois, E., Davies, P., Baley, C., 2012b. Improving the interfacial properties between flax fibres and PLLA by a water fibre treatment and drying cycle. Industrial Crops and Products 39, 31-39.

Le Moigne, N., Van Den Oever, M., Budtova, T., 2011. A statistical analysis of fibre size and shape distribution after compounding in composites reinforced by natural fibres. Composites Part A: Applied Science and Manufacturing 42, 1542-1550.

Lee, S.-H., Wang, S., 2006. Biodegradable polymers/bamboo fiber biocomposite with bio-based coupling agent. Composites Part A: Applied Science and Manufacturing 37, 80-91.

Lee, B.-H., Kim, H.-S., Lee, S., Kim, H.-J., Dorgan, J.R., 2009. Bio-composites of kenaf fibers in polylactide: role of improved interfacial adhesion in the carding process. Composites Science and Technology 69, 2573-2579.

Li, X., Tabil, L.G., Panigrahi, S., 2007. Chemical treatments of natural fiber for use in natural fiber-reinforced composites: a review. Journal of Polymers and the Environment 15, 25-33.

Morvan, C., Andème-Onzighi, C., Girault, R., Himmelsbach, D.S., Driouich, A., Akin, D.E., 2003. Building flax fibres: more than one brick in the walls. Plant Physiology and Biochemistry 41, 935-944. 
Nelson, M., O'Connor, R., 1964. Relation of certain infrared bands to cellulose crystallinity and crystal lattice type. Part II. A new infrared ratio for estimation of crystallinity in celluloses I and II. Journal of Applied Polymer Science 8 1325-1341.

Nielsen, L.E., Landel, R.F., 1974. Mechanical Properties of Polymers and Composites, vol. 2. Marcel Dekker, Inc., New York.

Ning, N., Fu, S., Zhang, W., Chen, F., Wang, K., Deng, H., Zhang, Q., Fu, Q., 2012 Realizing the enhancement of interfacial interaction in semicrystalline polymer/filler composites via interfacial crystallization. Progress in Polymer Science 37, 1425-1455.

Oksman, K., Skrifvars, M., Selin, J.-F., 2003. Natural fibres as reinforcement in polylactic acid (PLA) composites. Composites Science and Technology 63, 1317-1324.

Oksman, K., Mathew, A.P., Långström, R., Nyström, B., Joseph, K., 2009. The influence of fibre microstructure on fibre breakage and mechanical properties of natural fibre reinforced polypropylene. Composites Science and Technology 69 1847-1853.

Raj, G., Balnois, E., Baley, C., Grohens, Y., 2011. Role of polysaccharides on mechanical and adhesion properties of flax fibres in flax/PLA biocomposite. Internationa Journal of Polymer Science 2011, 1-11.

Reed, K.E., 1980. Dynamic mechanical analysis of fiber reinforced composites. Polymer Composites 1, 44-49.

Rong, M.Z., Zhang, M.Q., Liu, Y., Yang, G.C., Zeng, H.M., 2001. The effect of fiber treatment on the mechanical properties of unidirectional sisal-reinforced epoxy composites. Composites Science and Technology 61, 1437-1447.

Tokoro, R., Vu, D.M., Okubo, K., Tanaka, T., Fujii, T., Fujiura, T., 2008. How to improve mechanical properties of polylactic acid with bamboo fibers. Journal of Materials Science 43, 775-787.
Valadez-Gonzalez, A., Cervantes-Uc, J.M., Olayo, R., Herrera-Franco, P.J., 1999a. Effect of fiber surface treatment on the fiber-matrix bond strength of natural fiber reinforced composites. Composites: Part B 30, 309-320.

Valadez-Gonzalez, A., Cervantes-Uc, J.M., Olayo, R., Herrera-Franco, P.J., 1999b. Chemical modification of henequén fibers with an organosilane coupling agent. Composites: Part B 30, 321-331.

Wang, Y., Tong, B., Hou, S., Li, M., Shen, C., 2011. Transcrystallization behavior at the poly(lactic acid)/sisal fibre biocomposite interface. Composites Part A: Applied Science and Manufacturing 42, 66-74.

Wong, S., Shanks, R.A., Hodzic, A., 2004. Mechanical behavior and fracture toughness of poly(L-lactic acid)-natural fiber composites modified with hyperbranched polymers. Macromolecular Materials and Engineering 289, 447-456.

Xie, Y., Hill, C.A.S., Xiao, Z., Militz, H., Mai, C., 2010. Silane coupling agents used for natural fiber/polymer composites: a review. Composites Part A: Applied Science and Manufacturing 41, 806-819.

Yu, T., Ren, J., Li, S., Yuan, H., Li, Y., 2010. Effect of fiber surface-treatments on the properties of poly(lactic acid)/ramie composites. Composites Part A: Applied Science and Manufacturing 41, 499-505.

Zhou, Q. Greffe, L., Baumann, M.J., Malmstro, E., Teeri, T.T., Brumer III, H., 2005. Use of xyloglucan as a molecular anchor for the elaboration of polymers from cellulose surfaces: a general route for the design of biocomposites. Macromolecules 38 3547-3549.

Zhou, Z., Wang, J., Huang, X., Zhang, L., Moyo, S., Sun, S., Qiu, Y., 2012. Influence of absorbed moisture on surface hydrophobization of ethanol pretreated and plasma treated ramie fibers. Applied Surface Science 258, 4411-4416.

Ziegel, K.D., Romanov, A., 1973. Modulus reinforcement in elastomer composites. II Polymeric fillers. Journal of Applied Polymer Science 17, 1119-1131. 